\title{
Low-cost eddy covariance: a case study of evapotranspiration over agroforestry in Germany
}

\author{
Christian Markwitz and Lukas Siebicke \\ Bioclimatology, University of Goettingen, Büsgenweg 2, 37077 Göttingen, Germany \\ Correspondence: Christian Markwitz (christian.markwitz@ forst.uni-goettingen.de)
}

Received: 2 November 2018 - Discussion started: 18 February 2019

Revised: 26 June 2019 - Accepted: 13 July 2019 - Published: 3 September 2019

\begin{abstract}
Heterogeneous land surfaces require multiple measurement units for spatially adequate sampling and representative fluxes. The complexity and cost of traditional eddy covariance (EC) set-ups typically limits the feasible number of sampling units. Therefore, new low-cost eddy covariance systems provide ideal opportunities for spatially replicated sampling.

The aim of this study was to test the performance of a compact, low-cost pressure, temperature and relative humidity sensor for the application of evapotranspiration measurements by eddy covariance over agroforestry and conventional agriculture in Germany. We performed continuous low-cost eddy covariance measurements over agroforestry and conventional agriculture for reference at five sites across northern Germany over a period of 2 years from 2016 to 2017. We conducted side-by-side measurements using a roving enclosed-path eddy covariance set-up to assess the performance of the low-cost eddy covariance set-up.

Evapotranspiration measured with low-cost eddy covariance compared well with fluxes from conventional eddy covariance. The slopes of linear regressions for evapotranspiration comparing low-cost and conventional eddy covariance set-ups ranged from 0.86 to 1.08 for 5 out of 10 sites, indicating a $14 \%$ flux underestimation and a $8 \%$ flux overestimation relative to the conventional eddy covariance setup, respectively. Corresponding coefficients of determination, $R^{2}$, ranged from 0.71 to 0.94 across sites. The rootmean-square error for differences between latent heat fluxes obtained by both set-ups were small compared to the overall flux magnitude, with a mean and standard deviation of $34.23 \pm 3.2 \mathrm{~W} \mathrm{~m}^{-2}$, respectively, across sites.
\end{abstract}

The spectral response characteristics of the low-cost eddy covariance set-up were inferior to the eddy covariance set-up in the inertial sub-range of the turbulent spectrum. The water vapour flux co-spectrum of the low-cost eddy covariance set-up underestimated the theoretical slope of $-4 / 3$, stronger than the conventional eddy covariance set-up. This underestimation was mainly caused by the limited response time of the low-cost thermohygrometer being longer than $1 \mathrm{~s}$.

We conclude that low-cost eddy covariance sensors are an alternative to conventional eddy covariance sensors when, first, replicates are required and, second, the spatial variability of fluxes of the ecosystems of interest is larger than abovereported set-up-specific differences in fluxes.

\section{Introduction}

Eddy covariance (EC) is often the method of choice for measurements of the ecosystem-atmosphere exchange of water vapour, sensible heat, momentum and trace gases (Baldocchi, 2003, 2014; Farahani et al., 2007) over a variety of ecosystems. In ecosystems with a spatial variability of surface cover, the representativity of the measured fluxes is limited by the flux footprint extent (Schmid, 2002). Either the spatial variability of fluxes remains undetected (for small footprints) or can not be resolved explicitly (for large footprints). Such heterogeneous ecosystems require multiple towers for spatially representative flux sampling.

While the single-tower approach is still most common for ecosystem studies, a few studies have performed replicated EC measurements. Davis et al. (2010) studied carbon fluxes over an arable site in southeastern Ireland. Hollinger and Richardson (2005) used a set of two flux towers separated by a distance of $775 \mathrm{~m}$ for uncertainty estimation of EC flux measurements. Replication of sampling points was tradition- 
ally limited by high costs and the complexity of conventional EC set-ups. Therefore, there is increasing interest in the development of low-cost sensors for different applications in the biogeosciences.

Dias et al. (2007) proposed a cost-efficient direct attenuated EC set-up to measure latent heat fluxes, combining a sonic anemometer and a hygrometer of fast response. They applied a correction factor to the time-domain covariance between the vertical velocity and relative humidity measurements. Hill et al. (2017) presented a low-cost measuring setup to measure both $\mathrm{CO}_{2}$ and water vapour fluxes and discussed the value of increasing the number of measuring complexes for the statistical power of EC measurements in a variety of landscapes. Hill et al. (2017) concluded that at least four flux towers per site are required to confirm with a statistical confidence of $95 \%$ that the flux over 1 year is not 0 and therefore to accept with a statistical confidence of $5 \%$ that the annual flux is 0 . This is of major importance for an ecosystem that is heterogeneous at a scale larger than the flux footprint of a single tower.

Besides the replication of measurement units within one ecosystem, the ecosystem-to-ecosystem replication of sampling points is of importance to, e.g. assess the potential of forests for climate change mitigation and as a $\mathrm{CO}_{2} \operatorname{sink}(\mathrm{De}$ Stefano and Jacobson, 2018). The outcome of synthesis studies, e.g. on the water use of terrestrial ecosystems at global scale (Tang et al., 2014), could be strengthened by an increased number of flux-measuring units across ecosystems. Low-cost instrumentation can foster replicated EC measurements across the globe, especially in ecoregions that are currently only sparsely sampled, such as Africa, Oceania (except Australia) and South America (Hill et al., 2017 and Table 1 therein). With replicated measurements using low-cost equipment, effects of land-use changes or different agriculture management practices on turbulent fluxes can be assessed. A prominent example are flux measurements over heterogeneously shaped short-rotation alley-cropping systems (ACS) as one type of agroforestry (AF) in comparison to monocultural agriculture systems. Flux measurements over AF require replicated measurements to capture the spatial variability of the turbulent fluxes both at a single AF system and across multiple AF systems.

Our objectives are (i) to test the performance of a new EC measuring complex under field conditions for measuring half-hourly evapotranspiration over alley-cropping agroforestry systems and monocultural agriculture systems and (ii) to evaluate the low-cost measuring complex relative to conventional EC instrumentation.

\section{Material and methods}

\subsection{Site description}

The study is part of the SIGNAL (Sustainable intensification of Agriculture through agroforestry) project (http://www. signal.uni-goettingen.de/, last access: 21 August 2019), which aims to evaluate the sustainability of agroforestry in Germany. It is based on data collected at five sites in northern Germany (Fig. 1a). Each site consists of an agroforestry (AF) plot and a monocultural control (MC) plot. The agroforestry plots are alley-cropping systems, consisting of fast growing trees, such as willow (Salix), poplar (Populus) and black locust (Robinia), interleaved by either annually rotating crops or perennial grassland. The control plots consist of the same crop or grass type as planted between the tree strips and are managed as monocultural agriculture. Three sites undergo annual crop rotation (Dornburg, Forst and Wendhausen), while two systems are of a perennial grassland type (Mariensee and Reiffenhausen). The project design includes a fixed tree alley width of $10 \mathrm{~m}$, while alley length and number are variable across sites. Tree alley distances vary between 10, 24, 48 and $96 \mathrm{~m}$. The area covered by trees in relation to the whole agroforestry plot area varies between $6 \%$ and $72 \%$. Table A1 provides an overview of site locations, agroforestry geometry and stand characteristics.

We performed flux footprint climatology analyses with the flux footprint prediction online tool (http://footprint.kljun. net/, last access: 21 August 2019, Kljun et al., 2015). The flux footprint climatology is valid for the respective campaign and only for daytime data according to a global radiation of $R_{\mathrm{G}}>20 \mathrm{~W} \mathrm{~m}^{-2}$. We found a $90 \%$ flux magnitude contribution of the agroforestry plot in Forst and the monoculture plot in Dornburg and a $80 \%$ flux magnitude contribution of the agroforestry plots in Dornburg and Wendhausen. The smallest agroforestry system, Reiffenhausen, contributed the least to the measured turbulent flux, with $60 \%$. Outside the agroforestry plot, fluxes were affected by nearby crop fields within about $400 \mathrm{~m}$ of the flux tower in the northerly direction and by the forest within about $200 \mathrm{~m}$ of the flux tower in the southerly direction.

\subsection{Instrumental set-up}

\subsubsection{Standard meteorological measurements}

Continuous measurements of micrometeorological and standard meteorological variables have been performed since March 2016. At each agroforestry plot, one eddy covariance mast with a height of $10 \mathrm{~m}$ (Fig. 1b) was installed, and at each monocultural plot one eddy covariance mast with a height of $3.5 \mathrm{~m}$ (Fig. 1c) was installed. Each mast in the agroforestry and the monocultural plots was equipped with an identical instrumental set-up. An overview of all installed instruments is given in Table 1. The data were logged and stored on a CR6 

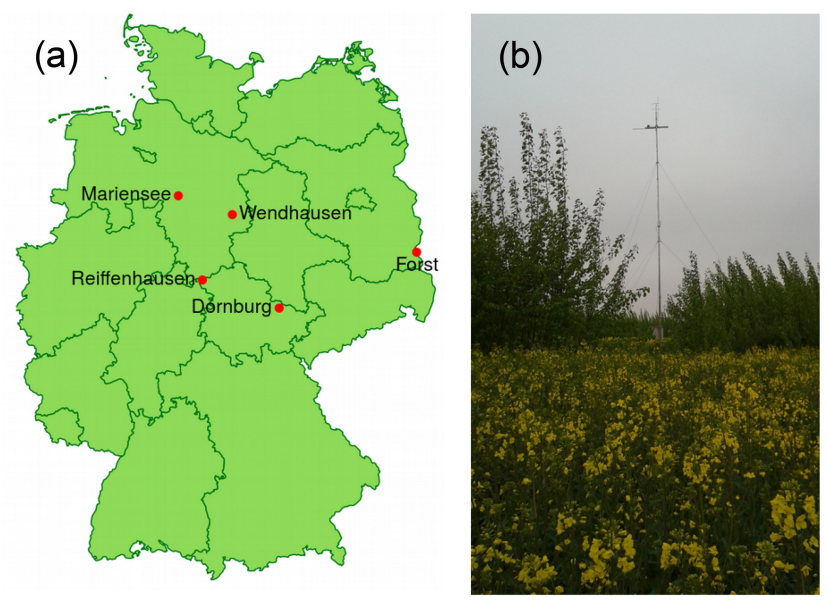

(c)

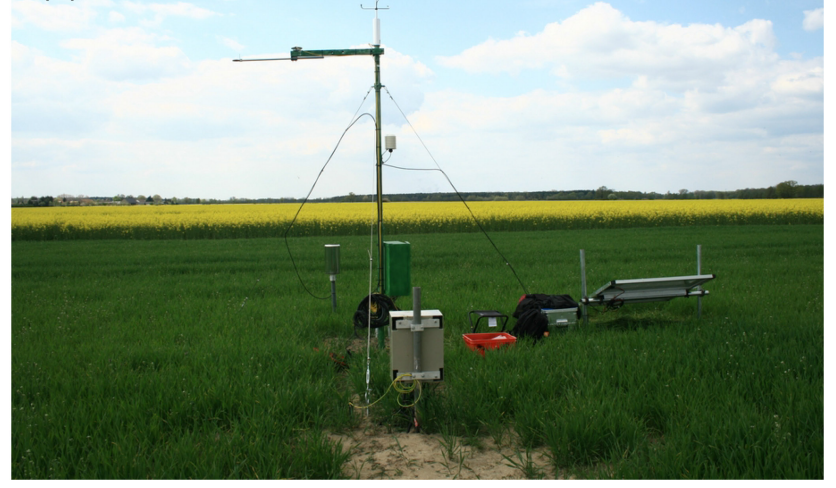

Figure 1. (a) SIGNAL sites (map source: Bundesamt für Kartographie und Geodäsie, 2011), (b) the agroforestry plot in Dornburg with eddy covariance mast and (c) the monocultural agriculture plot in Forst (Lower Lusatia) with eddy covariance mast.

data logger (Campbell Scientific, Inc., Logan, UT, USA). The meteorological data were regularly sent to a database via mobile phone network.

\subsubsection{Conventional eddy covariance installation}

Fluxes of sensible heat and momentum were continuously measured with a uSONIC-3 Omni (METEK GmbH, Elmshorn, Germany) ultrasonic anemometer. $\mathrm{CO}_{2}$ and water vapour fluxes were measured in campaigns during the vegetation periods of 2016 and 2017. During the 2016 campaign, fluxes were measured separately during two consecutive periods of 4 weeks at the agroforestry and monocultural plots, whilst in 2017 both plots were sampled simultaneously over a time period of approximately 4 weeks (see Table A2 for exact dates). During the campaigns, the instrumentation specified in Table 1 was complemented by a LI-7200 (LI-COR Inc., Lincoln, NE, USA) enclosed-path infrared gas analyser (Burba et al., 2012). The data were measured together with the three-dimensional wind velocity and the sonic temperature and stored on the same data logger (CR6, Campbell
Scientific, Inc., Logan, UT, USA) as used for the meteorological variables. The water vapour and $\mathrm{CO}_{2}$ mole fractions were sampled with a sampling frequency of $20 \mathrm{~Hz}$. The intake tube was of $1 \mathrm{~m}$ length and had an inner tube diameter of $5.3 \mathrm{~mm}$ (2016) and $8.2 \mathrm{~mm}$ (2017). The separation of the gas analysers intake tube relative to the centre of the sonic anemometer was different for each plot and is summarized in Table A3. The flow rate was kept constant at $15 \mathrm{slpm}$.

\subsubsection{Low-cost eddy covariance (EC-LC) installation}

The low-cost eddy covariance set-up shared the same ultrasonic anemometer (uSONIC-3 Omni) as used for the conventional EC set-up. The water vapour mole fraction was derived from the combined digital pressure, relative humidity and air temperature sensor BME280 manufactured by Robert Bosch $\mathrm{GmbH}$, Stuttgart, Germany (hereafter named thermohygrometer). Figure 2 depicts the low-cost set-up. The measuring principles of the air pressure sensor and the relative humidity sensor are resistive and capacitive, respectively. The temperature sensor readings are based on diode voltage measurements. The ultrasonic anemometer measured the threedimensional wind speed and the ultrasonic temperature at a frequency of $20 \mathrm{~Hz}$, whereas the thermohygrometer measured the air temperature, relative humidity and air pressure at a sampling frequency of $8 \mathrm{~Hz}$. The specified response time of the thermohygrometer for relative humidity measurements is $1 \mathrm{~s}$, in order to overcome $63 \%$ of the step change from $90 \%$ to $0 \%$ or $0 \%$ to $90 \%$ relative humidity at a $25^{\circ} \mathrm{C}$ air temperature.

The response time of the temperature sensor of the thermohygrometer was not explicitly stated. Therefore, we estimated the response time in a lab experiment. We exposed the temperature sensor to a rapid temperature change about $10^{\circ} \mathrm{C}$ warmer than ambient air temperature. The time constant $\tau$ was then directly proportional to the slope of the linear regression fit:

$t=\tau \ln \left(\frac{\vartheta(t=1)-\vartheta_{\text {Ambient }}}{\vartheta\left(t=t_{\text {var }}\right)-\vartheta_{\text {Ambient }}}\right)$,

with the measurement time, $t$, the air temperature at the first time step, $\vartheta(t=1)$, the ambient air temperature, $\vartheta_{\text {Ambient }}$, and air temperature at variable time step, $\vartheta\left(t=t_{\mathrm{var}}\right)$. The time constant achieved for the temperature sensor was $23.3 \pm$ $0.9 \mathrm{~s}$ as a mean of four replications. During the lab experiment the thermohygrometer was placed inside the same housing as deployed in the field.

The thermohygrometer was placed $0.5 \mathrm{~m}$ below the centre of the sonic anemometer in a polyvinyl chloride (PVC) housing to protect the thermohygrometer from precipitation. The PVC housing consisted of an outer and an inner cylinder. The inner cylinder was perforated on the top to provide a continuous air flow of $15 \mathrm{~L} \mathrm{~min}^{-1}$, which was generated by a ventilator (HA30101V3-0000-A99, Sunonwealth Electric Machine Industry Co. Ltd., Fresnes Cedex, France). The ven- 
Table 1. Instrumentation for flux and meteorological measurements used at all five agroforestry and five monocultural agriculture plots.

\begin{tabular}{|c|c|c|c|}
\hline Variable & Height $[\mathrm{m}]$ & Instrument & Company \\
\hline \multicolumn{4}{|l|}{ Standard meteorological measurements } \\
\hline $\begin{array}{l}\text { 3-D wind components, } u, v, w \text {, } \\
\text { sonic temperature, } T_{\mathrm{S}} \text {, } \\
\text { wind speed and -direction }\end{array}$ & $3.5,10$ & uSONIC-3 Omni & METEK GmbH, Elmshorn, Germany \\
\hline Net radiation, $R_{\mathrm{N}}$ & $3,9.5$ & NR-Lite2 net radiometer & Kipp \& Zonen, Delft, The Netherlands \\
\hline Global radiation, $R_{\mathrm{G}}$ & $3,9.5$ & CMP3 pyranometer & Kipp \& Zonen, Delft, The Netherlands \\
\hline $\begin{array}{l}\text { Relative humidity, } \mathrm{RH} \text {, } \\
\text { air temperature, } T\end{array}$ & 2 & $\begin{array}{l}\text { Hygro-thermo transmitter-compact } \\
\text { (Model 1.1005.54.160) }\end{array}$ & Thies Clima, Göttingen, Germany \\
\hline Precipitation & 1 & $\begin{array}{l}\text { Precipitation transmitter } \\
\text { (Model 5.4032.35.007) }\end{array}$ & Thies Clima, Göttingen, Germany \\
\hline Atmospheric pressure, ppp & 0.5 & $\begin{array}{l}\text { Baro transmitter } \\
\text { (Model 3.1157.10.000) }\end{array}$ & Thies Clima, Göttingen, Germany \\
\hline Ground heat flux, $G$ & -0.05 & Hukseflux HFP01 & Hukseflux, Delft, The Netherlands \\
\hline Soil temperature, $T_{\text {Soil }}$ & $\begin{array}{r}-0.02,-0.05 \\
-0.10,-0.25,-0.5\end{array}$ & DS18B20 & \\
\hline \multicolumn{4}{|c|}{ Conventional eddy covariance measurements } \\
\hline$u, v, w, T_{\mathrm{s}}$ & $3.5,10$ & uSONIC-3 Omni & METEK GmbH, Elmshorn, Germany \\
\hline Water vapour mole fraction, $C_{\mathrm{H}_{2} \mathrm{O}_{\mathrm{v}}}$ & $3.5,10$ & LI-7200 & LI-COR Inc., Lincoln, NE, USA \\
\hline Carbon dioxide mole fraction, $C_{\mathrm{CO}_{2}}$ & $3.5,10$ & LI-7200 & LI-COR Inc., Lincoln, NE, USA \\
\hline \multicolumn{4}{|c|}{ Low-cost eddy covariance measurements } \\
\hline$u, v, w, T_{\mathrm{S}}$ & $3.5,10$ & uSONIC-3 Omni & METEK GmbH, Elmshorn, Germany \\
\hline $\mathrm{RH}, T, \mathrm{ppp}$ & $3,9.5$ & BME280 & Robert Bosch GmbH, Stuttgart, Germany \\
\hline
\end{tabular}

tilator was placed below the thermohygrometer inside the inner cylinder. The volume of the inner cylinder was $98.1 \mathrm{~cm}^{3}$.

The absolute accuracy tolerance of the relative humidity sensor was specified as $\pm 3 \%$ for $20 \%$ to $80 \%$ relative humidity at $25^{\circ} \mathrm{C}$ air temperature. For the temperature sensor an absolute accuracy tolerance of $\pm 0.5^{\circ} \mathrm{C}$ at $25^{\circ} \mathrm{C}$ air temperature was given and for a temperature range of 0 to $65^{\circ} \mathrm{C}$ an absolute accuracy tolerance of $\pm 1^{\circ} \mathrm{C}$ was specified. The pressure sensor has an absolute accuracy tolerance of $\pm 1 \mathrm{hPa}$ for a pressure range from 300 to $1100 \mathrm{hPa}$ at air temperature between 0 and $65^{\circ} \mathrm{C}$ (Bosch Sensortec $\mathrm{GmbH}, 2016$ ).

Digital data from the thermohygrometer were recorded via the i2c protocol and stored on a Raspberry Pi model B+ (Raspberry Pi Foundation, Cambridge, UK). The thermohygrometer has very low power consumption of approximately $3.6 \mu \mathrm{A}$ at a sampling frequency of $1 \mathrm{~Hz}$. The power draw of the thermohygrometer is $9.4 \mathrm{e}-5 \mathrm{~W}$ at a measuring frequency of $8 \mathrm{~Hz}$, when powered with $3.3 \mathrm{~V}$ and if all three variables are measured at the same time. The Raspberry Pi has a maximum power consumption of about $1.1 \mathrm{~W}$.

The key potential of the low-cost EC set-up is for replicated measurements of evapotranspiration across different ecosystems. The relative cost of the low-cost set-up (featuring a sonic anemometer, a Raspberry Pi and the thermohygrometer of low cost) is often less then $10 \%$ of a typical con- ventional EC set-up. Besides a precipitation protection and a stable power supply, the thermohygrometer is also low maintenance. The mean time before failure of the sensor in our study was approximately 2 years.

\subsection{Flux computation}

\subsubsection{Conventional eddy covariance set-up}

Latent heat fluxes and sensible heat fluxes were calculated with the open source EddyPro ${ }^{\circledR}$ eddy covariance software (LI-COR, Inc., Lincoln, NE, USA, version 6.2.0).

The fluxes were computed as follows:

$$
\begin{aligned}
H & =\rho_{\mathrm{a}} c_{\mathrm{p}} \overline{w^{\prime} T_{\mathrm{s}}^{\prime}}, \\
\lambda E_{\mathrm{EC}} & =\lambda M_{\mathrm{H}_{2} \mathrm{O}_{\mathrm{v}}} \overline{w^{\prime} d_{\mathrm{H}_{2} \mathrm{O}_{\mathrm{v}}}^{\prime}},
\end{aligned}
$$

with the density of dry air, $\rho_{\mathrm{a}}$, the specific heat capacity at constant pressure, $c_{\mathrm{p}}$, the vertical velocity component, $w$, the ultrasonic temperature, $T_{\mathrm{s}}$, the latent heat of evaporation, $\lambda$, the molar mass of water vapour, $M_{\mathrm{H}_{2} \mathrm{O}_{\mathrm{v}}}$, and the molar density of water vapour, $d_{\mathrm{H}_{2} \mathrm{O}_{\mathrm{v}}}$. Primes denote deviations from the mean and overlines denote time averages.

Fluxes were calculated over a block averaging period of $30 \mathrm{~min}$. The horizontal wind component was rotated into the mean wind direction via double rotation 


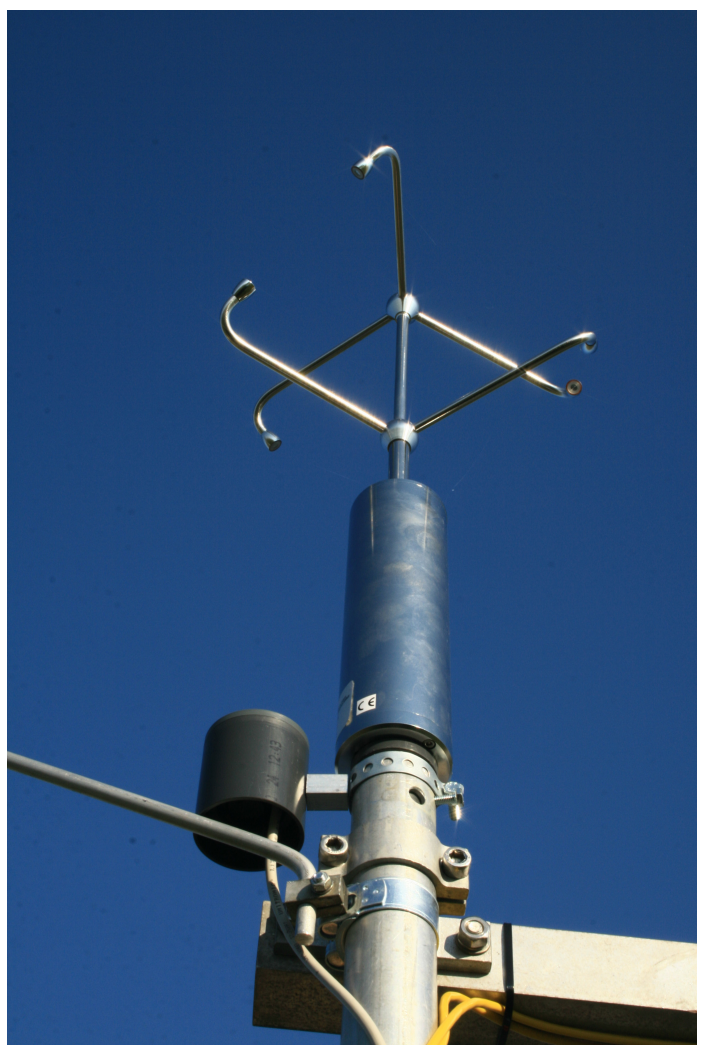

Figure 2. Low-cost eddy covariance instrumentation, featuring a uSONIC-3 Omni sonic anemometer and a BME280 thermohygrometer. The thermohygrometer is placed in a ventilated PVC housing below the sonic anemometer.

(Kaimal and Finnigan, 1994). Time lags between the ultrasonic anemometer and the intake tube of the LI-7200 gas analyser were calculated and corrected as a function of relative humidity (LI-COR, 2015). The effect of density fluctuations on the turbulent fluxes was corrected for by the Webb, Pearman and Leuning (WPL) correction (Webb et al., 1980) and the ultrasonic temperature was corrected for humidity effects (Schotanus et al., 1983). Fluxes of sensible and latent heat as well as momentum were filtered by removing all flux values corresponding to a flag of 2 , following the twostage quality control procedure of Mauder and Foken (2011). Latent heat fluxes below $-50 \mathrm{~W} \mathrm{~m}^{-2}$ and above $500 \mathrm{~W} \mathrm{~m}^{-2}$ were discarded. We further discarded latent heat fluxes according to the $97.5 \%$ percentile of the $\mathrm{H}_{2} \mathrm{O}$ variance, and spikes were removed following Vickers and Mahrt (1997). Through a quality check $9.6 \pm 3.2 \%$ of half-hourly latent heat fluxes obtained by the EC set-up were discarded and $10.4 \pm 3.8 \%$ of half-hourly latent heat fluxes obtained by the EC-LC set-up were discarded, as a mean over all five plots. Low-frequency and high-frequency losses were corrected by the procedures of Moncrieff et al. (2004) and Ibrom et al. (2007), respectively. Random uncertainties of fluxes were calculated following Mann and Lenschow (1994).

\subsubsection{Low-cost eddy covariance set-up}

The latent heat flux from the low-cost eddy covariance setups was calculated as the covariance between the vertical velocity and the water vapour mole fraction, again with the EddyPro $^{\circledR}$ eddy covariance software (LI-COR, Inc., Lincoln, NE, USA, version 6.2.0). The water vapour mole fraction, $C_{\mathrm{H}_{2} \mathrm{O}_{\mathrm{v}}}$, was derived from relative humidity, temperature and pressure measured with the thermohygrometer from the definition of the specific humidity, $q$, as the quantity of water vapour per quantity of moist air. The latter two quantities were expressed as the density of water vapour, $\rho_{\mathrm{H}_{2} \mathrm{O}_{\mathrm{v}}}$, and moist air, $\rho_{\mathrm{m}}$, respectively. The density of moist air is defined as the sum of the density of dry air, $\rho_{\mathrm{d}}$, and the density of water vapour.

$$
\begin{aligned}
q & =\frac{\rho_{\mathrm{H}_{2} \mathrm{O}_{\mathrm{v}}}}{\rho_{\mathrm{m}}} \\
& =\frac{\rho_{\mathrm{H}_{2} \mathrm{O}_{\mathrm{v}}}}{\rho_{\mathrm{d}}+\rho_{\mathrm{H}_{2} \mathrm{O}_{\mathrm{v}}}}
\end{aligned}
$$

We then replaced the density of water vapour and the density of dry air in Eq. (3) as per Eqs. (4) and (5), respectively,

$$
\begin{aligned}
\rho_{\mathrm{H}_{2} \mathrm{O}_{\mathrm{v}}} & =\frac{C_{\mathrm{H}_{2} \mathrm{O}_{\mathrm{v}}} \cdot M_{\mathrm{H}_{2} \mathrm{O}_{\mathrm{v}}}}{V_{\mathrm{m}}}, \\
\rho_{\mathrm{d}} & =\frac{p-e}{R_{\mathrm{d}} \cdot T_{\mathrm{A}}},
\end{aligned}
$$

with the molar mass of water vapour, $M_{\mathrm{H}_{2} \mathrm{O}_{\mathrm{v}}}=$ $18.02 \mathrm{~g} \mathrm{~mol}^{-1}$, the molar volume of air

$V_{\mathrm{m}}=\frac{\Re \cdot T_{\mathrm{A}}}{p}\left(\mathrm{~m}^{3} \mathrm{~mol}^{-1}\right)$,

the universal gas constant, $\Re=8.314 \mathrm{~J} \mathrm{~mol}^{-1} \mathrm{~K}^{-1}$, and the specific gas constant of dry air, $R_{\mathrm{d}}=287.058 \mathrm{~J} \mathrm{~kg}^{-1} \mathrm{~K}^{-1}$.

Solving Eq. (3) for $C_{\mathrm{H}_{2} \mathrm{O}_{v}}$ leads to the following water vapour mole fraction:

$C_{\mathrm{H}_{2} \mathrm{O}_{\mathrm{v}}}=\frac{q \Re(p-e)}{p M_{\mathrm{H}_{2} \mathrm{O}} R_{\mathrm{d}}(1-q)}$.

The specific humidity in Eq. (7) was calculated as a function of relative humidity, temperature and air pressure measurements from the thermohygrometer:

$q=0.622 \cdot \frac{e}{p}$.

The saturation vapour pressure, $E_{\mathrm{Sat}}$, and vapour pressure, $e$, in Eq. (8) were calculated using Eqs. (11) and (12), respectively.

The water vapour mole fraction is expressed as the wet mole fraction, thus the mass of water vapour molecules per total mass of air. Therefore, latent heat fluxes derived from the water vapour mole fraction need to be corrected for density effects (WPL correction, Webb et al., 1980) caused by 
temperature and water vapour fluctuations. The WPL correction requires true ambient air temperature measurements. Our fast measurements of the true air temperature obtained by the thermohygrometer were attenuated by the slow response time of the thermohygrometer temperature measurements. Additionally, the air temperature obtained by the thermohygrometer overestimated the ultrasonic temperature used as a reference, caused by a radiation effect from the grey PVC housing. Therefore, we derived a true air temperature for the WPL correction from the definition of the ultrasonic temperature, $T_{\mathrm{s}}$, and its dependency on air humidity:

$T_{\mathrm{s}}=T\left(1+0.32 \frac{e}{p}\right)$,

with the atmospheric pressure, $p$, to calculate a moisturecorrected temperature, which we used as an estimate of true air temperature, $T$ :

$T=\frac{T_{\mathrm{s}}}{\left(1+0.32 \frac{e}{p}\right)}$.

An initial value for the vapour pressure in Eq. (10) was calculated from an approximation of the saturation vapour pressure, $E_{\text {Sat }}$ (based on $T_{\mathrm{s}}$ ) (Stull, 1989) and from relative humidity $(\mathrm{RH})$ :

$$
\begin{aligned}
E_{\text {Sat }} & =0.6112 \exp \frac{17.6294 \cdot\left(T_{\mathrm{S}}-273.16\right)}{T_{\mathrm{S}}-35.86 \mathrm{~K}}, \\
e & =\frac{\mathrm{RH} \cdot E_{\mathrm{Sat}}}{100} .
\end{aligned}
$$

The derivation of the vapour pressure was iterated using Eqs. (9), (10) and (11).

We matched the water vapour mole fraction calculated from the thermohygrometer data and the velocity components measured with the ultrasonic anemometer according to the nearest-neighbour date values to address the two different sampling frequencies of 8 and $20 \mathrm{~Hz}$, respectively. The two data acquisition systems (the CR6 logger and the Raspberry $\mathrm{Pi}$, respectively) were regularly manually synchronized. In detail, the Raspberry Pi was synchronized with an online NTP server, whereas the CR6 logger was synchronized during regular maintenance visits.

A time lag between the anemometer and the thermohygrometer was corrected for in a preprocessing routine. The cross-correlation function (CCF) from the R-package tseries (Trapletti and Hornik, 2017) was used to detect the time lag between the vertical velocity component and the water vapour mole fraction. The respective time lag was extracted according to the maximum cross-correlation coefficient. The estimated lag time was used to merge the velocity components, $u, v$, and $w$, and the ultrasonic temperature with the nearest-neighbour water vapour mole fraction.

We applied the same flux corrections and quality checks to fluxes obtained by the EC-LC set-up as for the conventional EC set-up (see Sect. 2.3.1). The only difference was the correction of high-frequency losses, where we applied the correction following Moncrieff et al. (1997). The correction procedure was explicitly recommended by Moncrieff et al. (1997) for either open-path sensors or closed-path systems of very short and heated sampling lines.

The method is fully analytic and for each half-hour period the flux co-spectra are estimated from analytical formulations following Moncrieff et al. (1997) (Eqs. 12-18 therein). Those equations are a modified version of the formulas in Kaimal et al. (1972). The co-spectra are expressed as a function of the normalized frequency, which is a function of the natural frequency, measurement height, zero displacement height, wind speed and atmospheric stability.

We studied the impact of the different corrections on the raw turbulent evapotranspiration rates obtained by the ECLC set-up. We applied the single corrections separately on a test dataset from the agroforestry plot in Dornburg from 14 July to 12 August 2016. We assessed the impact of the following corrections on the raw evapotranspiration rates: (1) the fully analytic high-frequency co-spectral correction following Moncrieff et al. (1997), (2) the low-frequency cospectral correction following Moncrieff et al. (2004) and (3) the WPL correction following Webb et al. (1980). The corresponding results are presented in Sect. 3.3.

Linear regression analyses were performed between evapotranspiration obtained by the EC set-up and the EC-LC setup. We used the major axis linear regression method from the lmodel 2 function as part of the Imodel2 R-package (Legendre and Oksanen, 2018). The major axis linear regression method assumes equally distributed errors in both time series.

\subsection{Spectral analysis}

Commonly, high-frequency trace gas measurements (e.g. the water vapour mole fraction or $\mathrm{CO}_{2}$ mole fraction) taken by closed- or enclosed-path gas analysers are attenuated in the high-frequency range of the energy spectrum (Lenschow and Raupach, 1991). Attenuation is mainly caused by exchange processes (adsorption or desorption) of gas molecules with tubing walls (Leuning and Moncrieff, 1990; Ibrom et al., 2007). This effect is most severe for sticky gases, such as water vapour. In contrast, the temperature spectrum and cospectrum are assumed to be not attenuated by the molecular exchange processes with tubing walls, as the measurements are taken with a sonic anemometer, which is open path. Attenuation of the ultrasonic temperature and the wind velocity components is mainly caused by the path-averaging effect, especially at low wind speeds and at very high wavenumbers (Kristensen and Fritzjarrals, 1984), which is outside the inertial sub-range. Therefore, we quantified the frequency response characteristics of the EC and EC-LC set-ups by ensemble-averaged spectra and co-spectra of water vapour fluxes and compared them with temperature spectra and cospectra. 


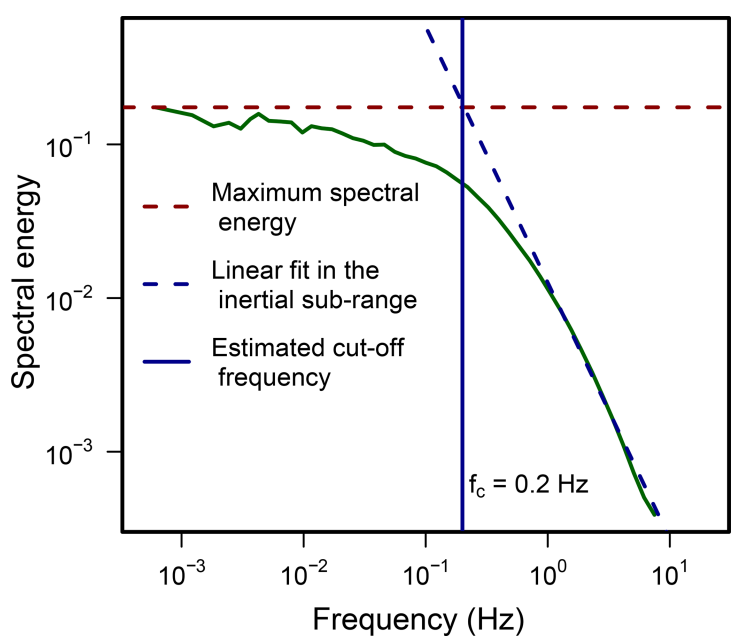

Figure 3. Sketch of the cut-off frequency estimation procedure with an exemplary true water vapour spectrum shown against frequency.

Additionally, we followed the Kolmogorov law (Kolmogorov, 1991), which describes a theoretical energy decrease with increasing frequency in the inertial sub-range of $-5 / 3$. The same theory formulates an energy decrease of $-2 / 3$ for scalars and $-4 / 3$ for covariances in the inertial subrange (Foken et al., 2004) if multiplied by the frequency. The inertial sub-range is the region of the spectrum where neither dissipation nor the generation of turbulent kinetic energy is important for the respective eddy. The eddies in the inertial sub-range receive energy from larger eddies and pass it on to smaller eddies (Stull, 1989). The corresponding results are presented in Sect. 3.5.

The spectral response characteristics of the LI-7200 gas analyser and the low-cost thermohygrometer were further investigated in terms of the cut-off frequency, $f_{\mathrm{c}}$, derived from true water vapour spectra. We estimated the cut-off frequency as the frequency of the intercept between the maximum water vapour spectral energy and the linear fit of the energy spectrum in the inertial sub-range (between 0.1 and $1 \mathrm{~Hz}$ ) on a double logarithmic scale (see Fig. 3 for clarification). From the cut-off frequency we estimated the sensors time constant, $\tau_{\mathfrak{c}}$, with the following relationship:

$\tau_{\mathrm{c}}=1 /\left(2 \pi f_{\mathrm{c}}\right)$.

\section{Results and discussion}

\subsection{Meteorological conditions}

The measuring period at the monocultural agriculture plot in Dornburg (16 June to 14 July 2016) was characterized by high air temperature with a maximum daily mean of $25^{\circ} \mathrm{C}$ and an average over the whole period of $18^{\circ} \mathrm{C}$ (Fig. 4a and
Table A4). Cumulative precipitation over the period was low at only $2 \mathrm{~mm}$ (Fig. 4a). The low amount of rainfall caused a rapid ripening of the crops, which had a significant impact on the turbulent fluxes: evapotranspiration decreased and the sensible heat fluxes increased during the measuring period of 4 weeks.

In contrast, the measuring period (14 July to 12 August 2016) at the agroforestry plot in Dornburg (Fig. 4b), about $500 \mathrm{~m}$ away from the monocultural plot, was characterized by warm (mean air temperature of $19^{\circ} \mathrm{C}$ ) and humid ambient conditions with a cumulative precipitation of about $50 \mathrm{~mm}$ and a mean vapour pressure deficit (VPD) of $6.41 \mathrm{hPa}$. At the time of installation of the EC set-up, the crops were already mature, whilst the trees were at the seasonal maximum of their productivity.

The weather conditions during the measuring period at the agroforestry plot in Reiffenhausen (12 August to 14 September 2016, Fig. 4c) were warm, with mean daily air temperatures above $15^{\circ} \mathrm{C}$ and a total mean temperature of $19.31^{\circ} \mathrm{C}$. The period was characterized by a few intense precipitation events with a cumulative sum of $26.3 \mathrm{~mm}$ (Table A4) and a mean VPD of $8.02 \mathrm{hPa}$.

The following measuring campaign in Wendhausen (3 May to 2 June 2017) was characterized by low mean VPD values of $5.4 \mathrm{hPa}$ at the agroforestry plot and $5.2 \mathrm{hPa}$ at the monocultural plot. At the beginning of the campaign, mean air temperature was at its lowest between 10 and $15^{\circ} \mathrm{C}$, whilst at the end air temperature was between 15 and $20^{\circ} \mathrm{C}$. The mean air temperature was $16.6^{\circ} \mathrm{C}$ at the agroforestry plot and $15.5^{\circ} \mathrm{C}$ at the monocultural plot (Fig. $4 \mathrm{~d}$ and Table A4). Plants were very productive in terms of transpiration both at the agroforestry (trees and crops) and the monocultural (only crops) plots.

In contrast, the campaign period in Forst ( 8 June to 8 July 2017) was very warm, with a mean air temperature of $21.4^{\circ} \mathrm{C}$ at the agroforestry plot and $21.2^{\circ} \mathrm{C}$ at the monocultural plot. High VPD values of around $12 \mathrm{hPa}$ indicate dry ambient conditions.

\subsection{Evapotranspiration rates from conventional and low-cost eddy covariance}

Diel cycles of evapotranspiration were well represented by the EC-LC set-up compared to the EC set-up on a $30 \mathrm{~min}$ timescale (Fig. 5) at all sites. On a longer timescale (over a period of 4 weeks) the EC-LC set-up showed changes in daily summed evapotranspiration rates from higher sums $(\approx$ $\left.6 \mathrm{mmd}^{-1}\right)$ at the beginning and lower sums $\left(\approx 3 \mathrm{mmd}^{-1}\right)$ at the end of the measuring period (from 16 June to 14 July 2016) at the monocultural agriculture plot in Dornburg, in the same way as the EC set-up did (Fig. 5f). We interpret this as a result of the ripening process of the crops. The ripening process was intensified by an exceptionally low cumulative precipitation of about $2 \mathrm{~mm}$ over the entire campaign period (Fig. 4a) and a resulting low soil water content (not shown). 


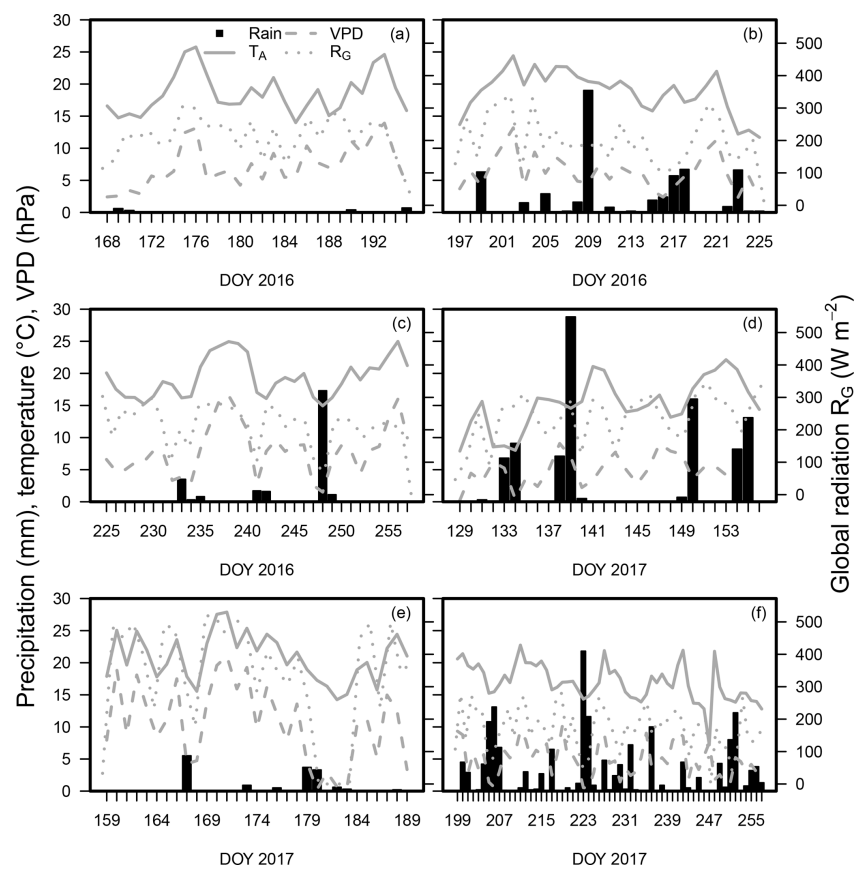

Figure 4. Daily averaged air temperature, vapour pressure deficit (VPD), daily summed precipitation and averaged global radiation, $R_{\mathrm{G}}$, for the following plots in each panel: Dornburg monoculture (a), Dornburg agroforestry (b), Reiffenhausen agroforestry (c), Wendhausen (d), Forst (e) and Mariensee (f). For Wendhausen, Forst and Mariensee, we took the average between the agroforestry and monocultural plot to provide a general overview of the meteorological conditions during the campaign. The averaging was done because both plots at the three sites were sampled simultaneously and the distance between both plots was $600 \mathrm{~m}$ maximum. We assumed similar weather conditions.

\subsection{Effect of spectral and WPL corrections on evapotranspiration rates from low-cost eddy covariance}

A linear regression analysis between the uncorrected and the fully corrected evapotranspiration rates yielded a slope of $0.74\left(R^{2}=99 \%\right)$ (Fig. 6). The applied corrections accounted for an increase of $26 \%$ of the overall flux magnitude.

The low-frequency co-spectral correction, following Moncrieff et al. (2004), accounted for $1 \%$ of the fully corrected flux, which was the smallest contribution of all corrections to a flux magnitude increase.

The WPL correction yielded an increase in the flux magnitude of about $2 \%$. Other studies found an increase in the mean latent heat flux of 5.6\% (Mauder and Foken, 2006) when the WPL correction was applied. In the study of Mauder and Foken (2006), the WPL-corrected latent heat flux measured with a LI-7500 open-path EC system was compared with an uncorrected flux from the same EC complex.
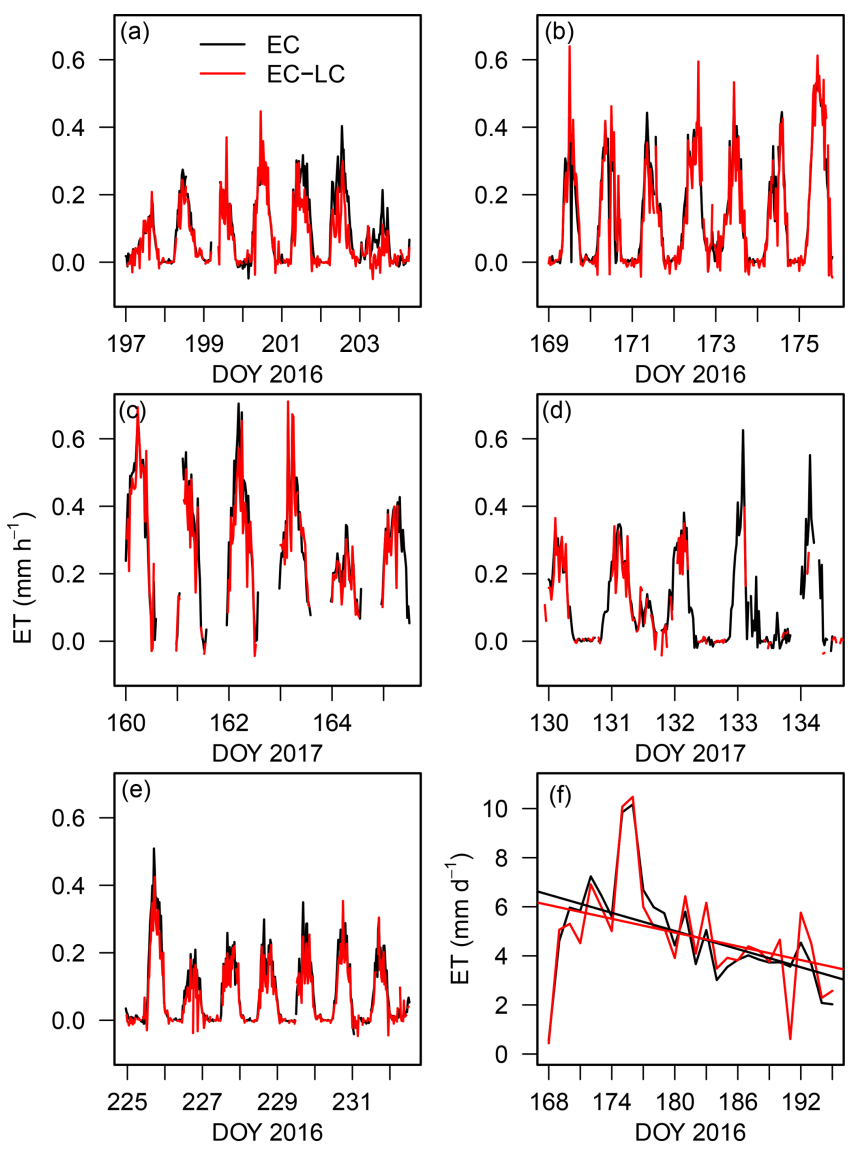

Figure 5. Half-hourly evapotranspiration rates of 1 exemplary week, measured with the conventional EC (black) and the ECLC set-up (red) for Dornburg agroforestry (a), Dornburg monoculture (b), Forst agroforestry (c), Wendhausen agroforestry (d), and Reiffenhausen agroforestry (e). Panel (f) shows time series of daily summed evapotranspiration for the EC and EC-LC set-ups for Dornburg monoculture over the whole campaign period (from 16 June to 14 July 2016). We included the linear trend lines with a slope of $-0.1232 \mathrm{mmd}^{-1}$ and a $p$ value of 0.009595 (black line) for the EC set-up and a slope of $-0.09337 \mathrm{mmd}^{-1}$ with a $p$ value of 0.06549 (red line) for the EC-LC set-up.

The high-frequency correction, following Moncrieff et al. (1997), accounted for $23 \%$ of the fully corrected flux, which was the largest contribution of all corrections to a flux magnitude increase. We interpret the high contribution of the correction from Moncrieff et al. (1997) as a result of the low response time of the thermohygrometer. In Ibrom et al. (2007) the low-pass filtering properties of the closed-path system led to an underestimation of the measured latent heat flux and resulted in a necessary correction of $42 \%$.

The overall impact of spectral corrections on a change of the turbulent latent heat fluxes was stronger for the EC-LC set-up compared to the EC set-up. Here, we quantify the overall impact of spectral corrections on latent heat fluxes in terms of the spectral correction factor $(\mathrm{SCF})$ calculated 


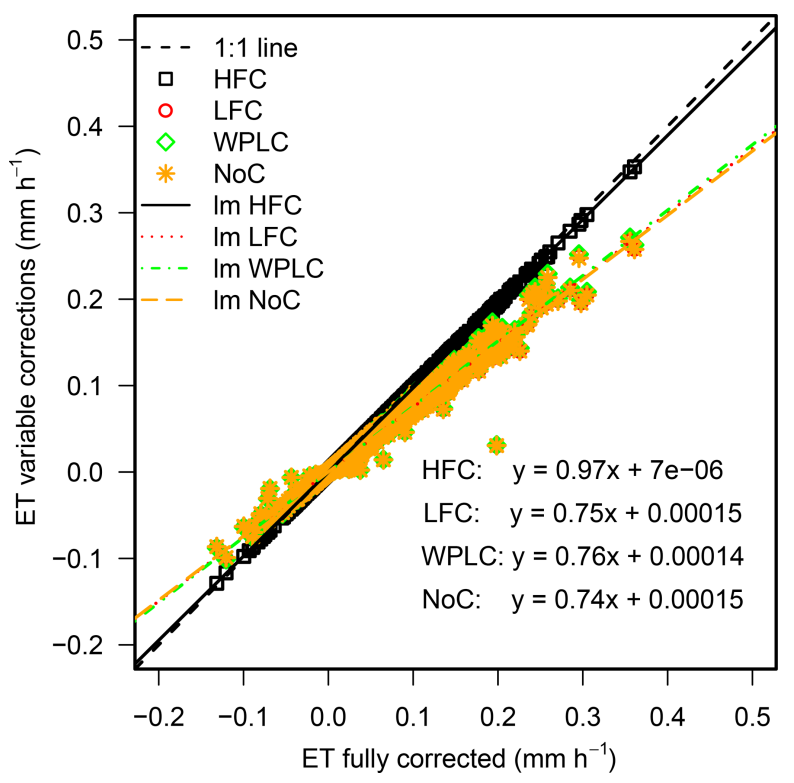

Figure 6. Evapotranspiration rates with the following corrections applied separately: (1) the high-frequency co-spectral correction following Moncrieff et al. (1997) (HFC, black squares), (2) the lowfrequency co-spectral correction following Moncrieff et al. (2004) (LFC, red circles), (3) WPL correction following Webb et al. (1980) (WPLC, green diamonds) and (4) no correction (NoC, yellow stars) vs. the fully corrected evapotranspiration rates of the EC-LC dataset from Dornburg agroforestry. The best fit line with the same colours as the corresponding data points and the linear regression results for the respective corrections are also shown. The linear regression is based on 1381 data points gathered during the campaign from the 14 July to 12 August 2016.

for each $30 \mathrm{~min}$ period. The $30 \mathrm{~min}$ SCF was multiplied with the respective uncorrected flux. A SCF larger than 1 indicates a flux magnitude increase, whereas a SCF lower than 1 indicates a flux magnitude decrease. Box and whisker plots of $30 \mathrm{~min}$ SCFs for each site and each set-up are shown in Fig. 7a. We found a mean SCF of $1.96 \pm 0.64$ for the ECLC set-up and $1.14 \pm 0.05$ for the EC set-up across all sites, indicating a mean flux magnitude increase of $96 \%$ for the EC-LC set-up and a mean flux magnitude increase of $14 \%$ for the EC set-up. The mean SCF presented here integrates both night and daytime periods. Thus, a high SCF during night-time with commonly low latent heat fluxes leads to a smaller change of the flux magnitude than during daytime, when fluxes are commonly high. Therefore, we also present the sum of $30 \mathrm{~min}$ evapotranspiration (ET) rates corrected for spectral losses and the sum of the total ET attributed to the spectral corrections in Fig. 7b. The part of the total corrected ET attributed to the spectral corrections was higher for the EC-LC set-up compared to the EC set-up and amounted on average to $42.7 \pm 14.1 \%$ of total ET for the EC-LC set-up and $9.3 \pm 3.3 \%$ of total ET for the EC set-up.

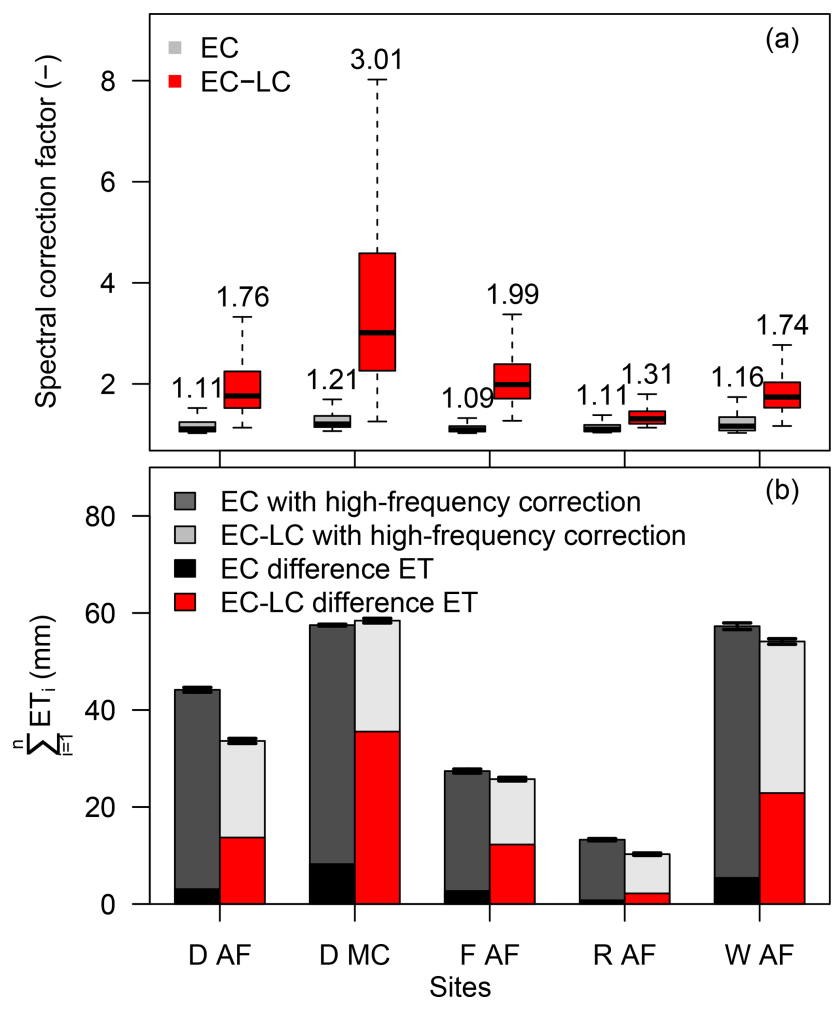

Figure 7. (a) Box and whisker plot of spectral correction factors for the EC (grey) and the EC-LC (red) set-up for all sites. Values above the bars correspond to the median spectral correction factor and (b) cumulative evapotranspiration rates for the EC and EC-LC setups for all sites: Dornburg agroforestry (D AF), Dornburg monoculture (D MC), Forst agroforestry (F AF), Wendhausen agroforestry (W AF) and Reiffenhausen agroforestry (R AF) over the respective campaign periods (Table A2). The error bars in (b) correspond to the summed random uncertainties. The black and red bars correspond to that part of the total ET attributed to the high-frequency correction for the EC and EC-LC set-up, respectively. Incomplete records with either EC or EC-LC missing were omitted.

Across sites, we found the highest median spectral correction factor of 3.01 and the highest part of the total corrected ET attributed to the spectral corrections of $60.9 \%$ for the EC-LC set-up at the monocultural agriculture plot in Dornburg. We interpret this as a measurement height dependency of the spectral corrections. The measurement height at the agroforestry plots was $10 \mathrm{~m}$ and at the monocultural agriculture plots the measurement height was $3.5 \mathrm{~m}$. We assume that high-frequency eddies are more likely close to the surface. Therefore, a detected turbulent signal at the lower measurement height would be shifted towards high frequencies compared to the detected turbulent signal at the higher measurement height (Aubinet et al., 2012). If a sensor is not capable of detecting the turbulent signal in the high-frequency range of the spectrum, the signal is attenuated and needs to be corrected. 


\subsection{Sensor cut-off frequency and time constant}

The nominal time response of the relative humidity sensor as part of the thermohygrometer yields a theoretical sensor cut-off frequency of $0.16 \mathrm{~Hz}(6.3 \mathrm{~s})$ calculated from Eq. (13).

Under field conditions we observed a mean cut-off frequency of $0.063 \pm 0.02 \mathrm{~Hz}$ for the low-cost thermohygrometer and $0.3 \pm 0.2 \mathrm{~Hz}$ for the LI-7200 gas analyser across five plots and all humidity classes (from $30 \%$ to $90 \%$ relative humidity bins). The respective mean time constant was $2.8 \pm 1 \mathrm{~s}$ for the low-cost thermohygrometer and $0.6 \pm 0.3 \mathrm{~s}$ for the LI7200 gas analyser (see Fig. 8). For both sensors we found an exponential increase in the time constant with relative humidity (see Fig. 8).

Under field conditions, the cut-off frequency and the respective time constant of the thermohygrometer were inferior to the one given in the specifications. We interpret this as caused by the design of the enclosure. The thermohygrometer is placed at the end of a cylinder with the ventilator directly below, so that the flow velocity is decelerated. Subsequently, the decelerated flow velocity leads to a limited signal response. One suggestion for improvement of the frequency response would be to place the thermohygrometer inside a longer tube with a freely moving air stream. This ensures a faster air exchange inside the measurement cell of the thermohygrometer and hence a faster response time.

\subsection{Spectral analysis}

\subsubsection{Ensemble-averaged spectra of the water vapour mole fraction and sonic temperature and their dependency on relative humidity}

The match of the water vapour mole fraction spectra with the theoretical $-2 / 3$ slope was found to be dependent on relative humidity. We observed the least deviation of the water vapour spectra obtained by the EC and EC-LC set-ups from the theoretical $-2 / 3$ slope for low relative humidity (Fig. 9). The relative humidity dependency of the water vapour spectra is a known feature for closed- and enclosed-path gas analysers. Fratini et al. (2012) reported the same behaviour for both short $(4 \mathrm{~m})$ and very short $(1 \mathrm{~m})$ sampling lines. The so-called "amplitude attenuation effect" (Fratini et al., 2012) was explained by Ibrom et al. (2007) as a result of absorption and desorption of water vapour molecules by hygroscopic particles inside the tube. Absorption and desorption processes are more pronounced at higher relative humidity and follow an exponential dependency on increasing relative humidity (Fratini et al., 2012; Ibrom et al., 2007).

The spectral response characteristics of the EC set-up were superior to the ones from the EC-LC set-up. The water vapour spectra from the EC-LC set-up deviated more from the theoretical $-2 / 3$ slope than the EC set-up in the inertial sub-range (between 0.1 and $1 \mathrm{~Hz}$ ) (Fig. 9). The ultrasonic temperature spectra followed a slope of $-2 / 3$ in the partic-

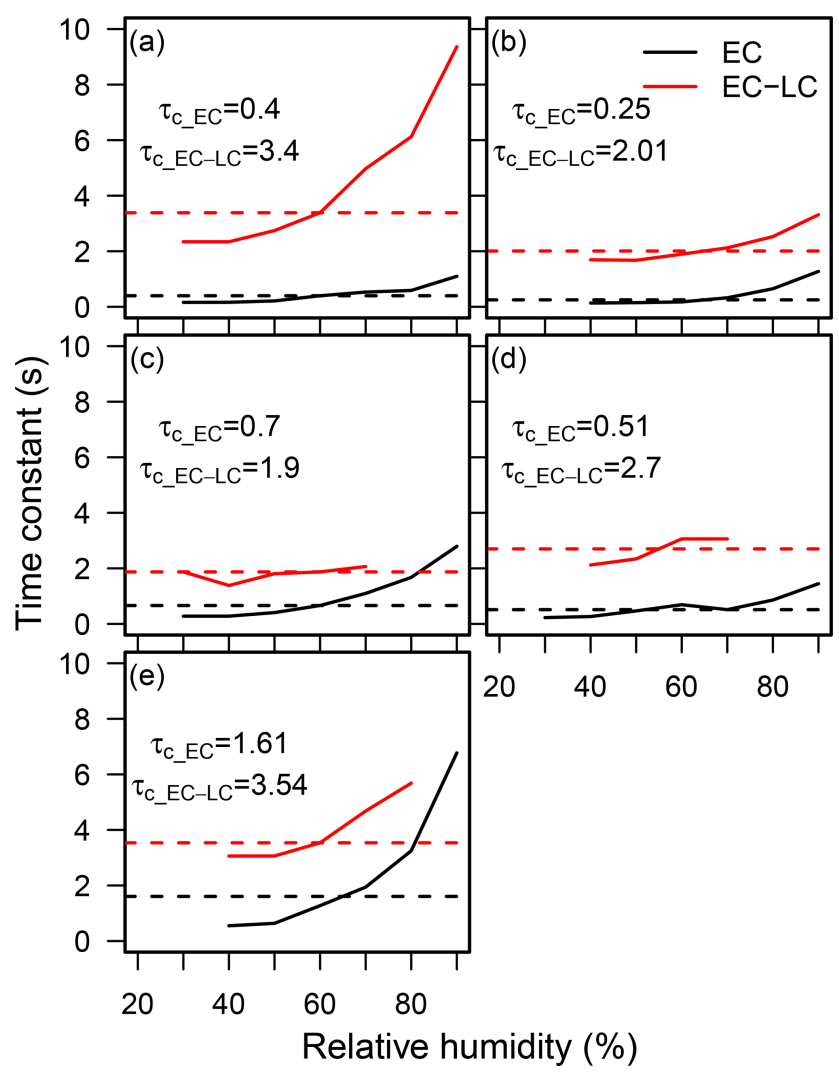

Figure 8. Time constant against relative humidity for the LI-7200 (black solid lines) and the thermohygrometer (red solid lines). The dashed lines have the same colour coding as the data shown, and the values written correspond to the mean time constant for the respective sensors across all relative humidity classes. Sites correspond to Dornburg agroforestry (a), Dornburg monoculture (b), Forst agroforestry (c), Reiffenhausen agroforestry (d) and Wendhausen agroforestry (e).

ular range of the energy spectrum, as the measurements are open path.

For frequencies higher than $1 \mathrm{~Hz}$, an increase in the spectral energy of water vapour for two out of five plots and both set-ups (i.e. Forst and Wendhausen agroforestry, Fig. 9c and d) was observed, whereas the water vapour spectral energy increase for the agroforestry and monocultural plots in Dornburg and Reiffenhausen agroforestry was only found for the EC-LC set-up. We interpret the spectral energy increase in water vapour in the particular frequency range as sensor noise, as indicated by the $f^{1}$ slope for white noise (Eugster and Plüss, 2010) in Fig. 9. The ultrasonic temperature spectra showed a slight spectral energy increase from frequencies higher than 4 to $5 \mathrm{~Hz}$, which we interpret as an attenuation effect caused by the path-averaging (Kristensen and Fritzjarrals, 1984).

The observed noise of the water vapour spectra obtained by the EC set-up at the agroforestry plots of Forst and Wendhausen (Fig. 9c and d) might be caused by the different tube 


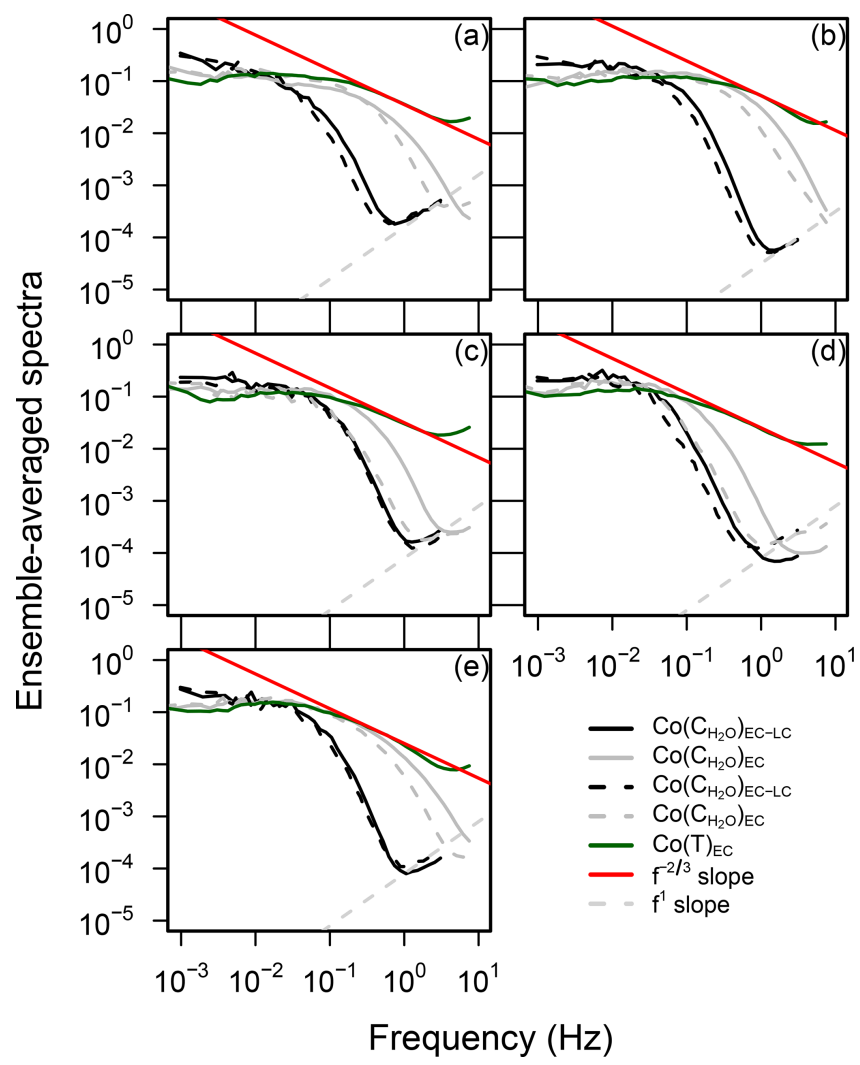

Figure 9. Ensemble-averaged normalized water vapour and temperature spectra for relative humidity thresholds of $60 \%$ (solid lines) and $80 \%$ (dashed lines) vs. the natural frequency. Spectra of the EC set-up (grey) and the EC-LC set-up (black) are shown. Panels correspond to plots: Dornburg agroforestry (a), Dornburg monoculture (b), Forst agroforestry (c), Wendhausen agroforestry (d) and Reiffenhausen agroforestry (e). Spectra were filtered for lowquality data, corresponding to a flag of 2 , following the procedure of Mauder and Foken (2011) and according to spike removal methods described in Vickers and Mahrt (1997). Relative humidity classes correspond to ancillary relative humidity measurements.

diameters used in 2016 and 2017. In 2017 a thicker tube, with an inner diameter of $8.2 \mathrm{~mm}$, was used compared to 2016 (inner tube diameter of $5.3 \mathrm{~mm}$ ). In both years, a flow rate of $15 \mathrm{slpm}$ was applied. The change in the inner tube diameter led to more turbulent conditions within the thinner tube than within the thicker tube. The thinner tube had a Reynolds number of 3950.6 (towards turbulent flow) and the thicker tube had a Reynolds number of 2551.71 (towards laminar flow).

\subsubsection{Ensemble-averaged co-spectra of the water vapour flux and sensible heat flux}

The water vapour flux co-spectra deviated negatively from the theoretical $-4 / 3$ slope for the EC and EC-LC set-ups between a normalized frequency of 0.1 and 8 (the inertial sub-range) for all sites (Fig. 10). The deviation from the

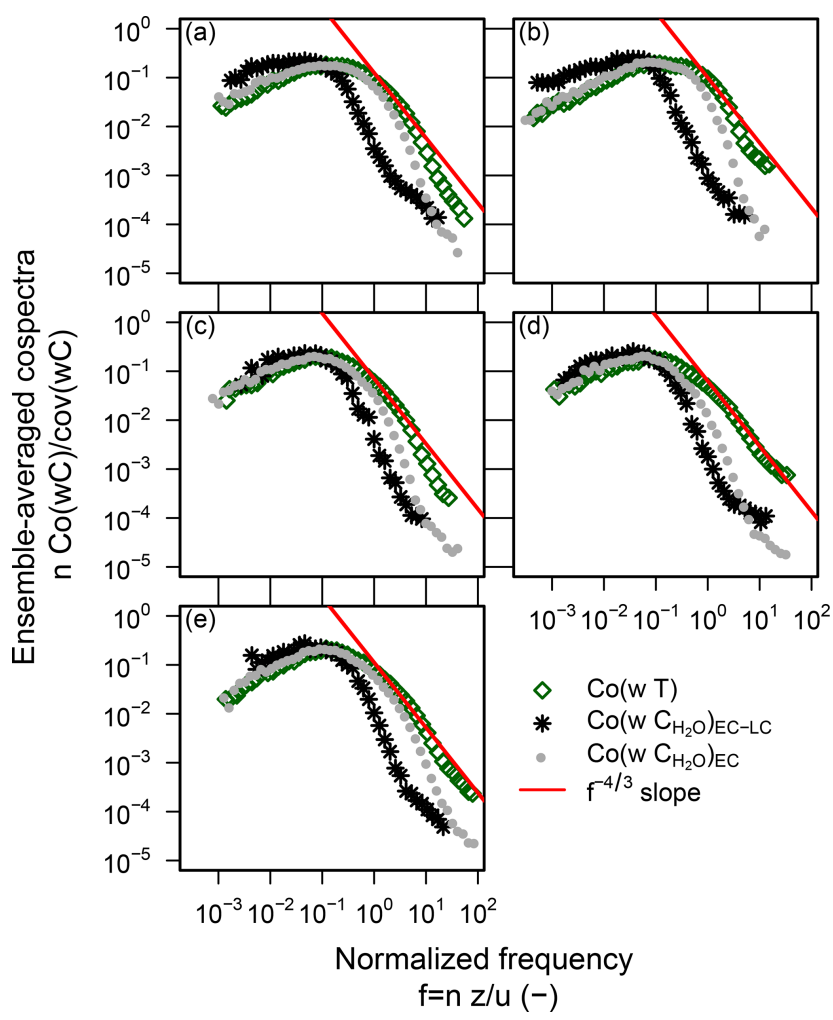

Figure 10. Ensemble-averaged co-spectra of the water vapour flux for the EC and the EC-LC set-ups (grey and black dots, respectively) and the co-spectrum of the sensible heat flux (green dots) vs. the normalized frequency over the entire campaign period for Dornburg agroforestry (a), Dornburg monoculture (b), Forst agroforestry (c), Wendhausen agroforestry (d) and Reiffenhausen agroforestry (e). Co-spectra shown correspond to an unstable stratified atmosphere, according to a Monin-Obukhov length between $-650<L<0$. Co-spectra were filtered for low-quality data, corresponding to a flag of 2 , following the procedure of Mauder and Foken (2011) and according to spike removal methods described in Vickers and Mahrt (1997).

$-4 / 3$ slope in this particular frequency range was strongest for the EC-LC set-up, which is a result of the limited spectral response characteristics of the thermohygrometer. As discussed in Sect. 3.4, the response time of the thermohygrometer was lower than given in the specifications.

The water vapour flux co-spectra of the conventional EC set-up at the agroforestry plots of Forst and Wendhausen (Fig. 10c and d) showed a stronger attenuation in the inertial sub-range, compared to the agroforestry plot and the monocultural agriculture plot in Dornburg and the agroforestry plot in Reiffenhausen (Fig. 10a, b and e). That was likely caused by the different tube diameter at the respective plots and the effect on the turbulence characteristics inside the tubes, as discussed in Sect. 3.5.1.

At normalized frequencies higher than 8, we found a slope decrease in the water vapour flux co-spectra obtained by the EC-LC set-up at all sites, which we interpret as an effect of 
sensor noise. Assuming that the vertical wind velocity measurements are unaffected by sensor noise, only the thermohygrometer measurements contribute to the slope decrease in the water vapour flux co-spectra found in Fig. 10 for the EC-LC set-up.

In the low-frequency range (for a normalized frequency $<$ 0.1 ) of the turbulent spectrum, the normalized water vapour co-spectrum obtained by the EC-LC set-up was higher than the temperature co-spectrum (Fig. 10). We interpret this finding as an effect of aliasing, which is an increased spectral energy in the low-frequency range due to an incorrect representation of the high frequencies (Foken, 2008). This implies a too high sampling frequency relative to the sensor response time. The effect of aliasing was also observed for the EC cospectrum but was much lower compared to the EC-LC set-up.

\subsection{Water vapour molar densities from the thermohygrometer and the LI-7200 gas analyser}

The water vapour molar density calculated from the thermohygrometer output was shown to be a smoothed version of the water vapour molar density directly measured by the LI-7200 gas analyser, as shown for a time period of $1 \mathrm{~h}$ for the agroforestry plot in Dornburg in Fig. 11. The low-frequency fluctuations were captured, whereas the highfrequency fluctuations were attenuated. A linear regression analysis between both water vapour molar densities yielded a $R^{2}$ value of 0.85 (based on 29419 data points). We interpret the smoothed water vapour molar density calculated by the thermohygrometer set-up as an effect of the longer response time of the thermohygrometer and the limited sampling frequency of $8 \mathrm{~Hz}$. Spectral analysis of the water vapour mole fraction (Sect. 3.5.1 and Fig. 9) derived from the thermohygrometer confirmed the attenuation of high frequencies by the thermohygrometer. The water vapour spectra from the thermohygrometer showed a strong deviation from the theoretical $-2 / 3$ slope and from the temperature spectrum at frequencies higher than $0.1 \mathrm{~Hz}$. For frequencies lower than $0.1 \mathrm{~Hz}$ the water vapour spectra compared well with the temperature spectrum.

The molar density derived from the thermohygrometer was on average about $100 \mathrm{mmol} \mathrm{m}^{-3}$ higher than the molar density measured by the LI-7200 gas analyser during the $1 \mathrm{~h}$ period. A mean value of $606.32 \mathrm{mmol} \mathrm{m}^{-3}$ was found for the thermohygrometer and $514.8 \mathrm{mmol} \mathrm{m}^{-3}$ for the LI-7200 gas analyser. We interpret the higher water vapour density derived from temperature, relative humidity and air pressure measurements from the thermohygrometer as an effect of the temperature measurements from the thermohygrometer. We found a $5{ }^{\circ} \mathrm{C}$ higher air temperature from the thermohygrometer compared to the sonic temperature under clear sky conditions. The temperature difference is caused by a radiation effect originating from the PVC housing.

In addition, the temperature measurements from the thermohygrometer were attenuated compared to the sonic tem-

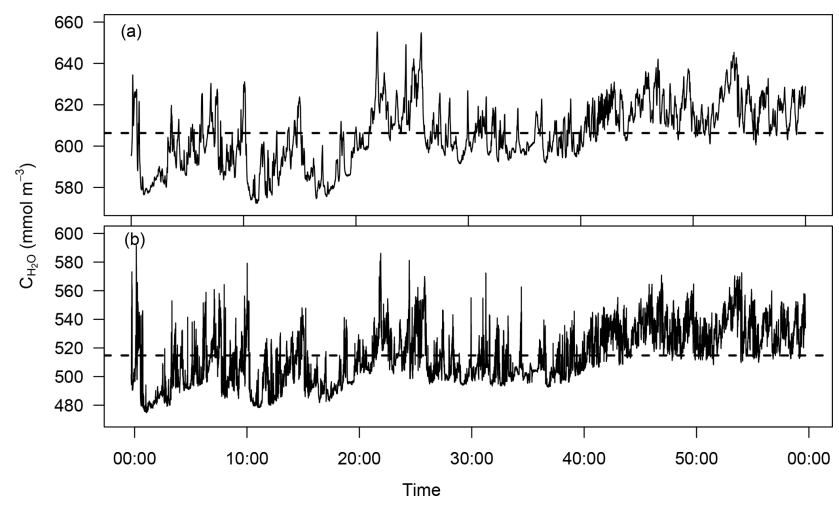

Figure 11. Water vapour molar density time series (solid line) and mean (dashed line) for the thermohygrometer (a) and the LI-7200 gas analyser (b) at the Dornburg agroforestry plot. The time series represent a $1 \mathrm{~h}$ period from 14:00 to 15:00 LT on 19 July 2016.

perature. We interpret this as an inertia effect of the thermohygrometer. So, if the thermohygrometer complex has a higher thermal mass than the ambient air, the temperature measurements taken by the thermohygrometer are attenuated in the high-frequency range. As the attenuation effect was not found in the relative humidity measurements, we assume that the relative humidity measurements were independent of temperature measurements, and therefore relative humidity was not attenuated in the same way as air temperature. Subsequently, relative humidity fluctuations were conserved and could be used for the calculations of the water vapour mole fraction. In general, the deviation from the mean is of higher interest than the mean itself for the EC method (Baldocchi, 2014). As long as the relative humidity fluctuations are conserved in the calculations of the water vapour mole fraction, a plausible covariance between the water vapour mole fraction and the vertical velocity can be calculated.

\subsection{Linear regressions of latent heat fluxes from conventional and low-cost eddy covariance}

Results of a linear regression analysis between evapotranspiration rates obtained by the EC and EC-LC set-ups revealed a dependency of the evapotranspiration rates on the highfrequency co-spectral correction method used. Evapotranspiration rates obtained by the EC-LC set-up using the Ibrom et al. (2007) high-frequency co-spectral correction underestimated evapotranspiration rates obtained by EC using the high-frequency correction following Ibrom et al. (2007) (always used for the EC set-up) at all sites (Table 2). The largest underestimation was $32 \%$ (Forst agroforestry) and the smallest underestimation was $13 \%$ (Dornburg agroforestry), with a median underestimation of $22 \%$ across all five plots.

In contrast, evapotranspiration estimates obtained by the EC-LC set-up using the Moncrieff et al. (1997) highfrequency co-spectral correction revealed an underestimation of evapotranspiration rates by the EC-LC set-up of $14 \%$, 
Table 2. Major axis linear regression of evapotranspiration from EC-LC vs. EC, using two high-frequency correction methods (Ibrom et al., 2007; Moncrieff et al., 1997). The slopes include the $\pm 2.5 \%$ confidence interval. The root-mean-square error (RMSE) and the coefficient of determination $\left(R^{2}\right)$ are given.

\begin{tabular}{|c|c|c|c|c|c|c|}
\hline \multirow[t]{3}{*}{ Site } & \multicolumn{6}{|c|}{ Correction method } \\
\hline & \multicolumn{3}{|c|}{ Ibrom et al. (2007) } & \multicolumn{3}{|c|}{ Moncrieff et al. (1997) } \\
\hline & Slope/intercept & $R^{2}$ & $\begin{array}{r}\text { RMSE } \\
\left(\mathrm{W} \mathrm{m}^{-2}\right)\end{array}$ & Slope/intercept & $R^{2}$ & $\begin{array}{r}\text { RMSE } \\
\left(\mathrm{W} \mathrm{m}^{-2}\right)\end{array}$ \\
\hline Dornburg AF & $0.87 \pm 0.034 /-9.04$ & 0.71 & 36.0 & $0.94 \pm 0.036 /-10.87$ & 0.71 & 35.13 \\
\hline Dornburg MC & $0.78 \pm 0.030 /-4.3$ & 0.71 & 50.8 & $1.08 \pm 0.027 /-5.12$ & 0.86 & 34.31 \\
\hline Forst AF & $0.68 \pm 0.026 /-0.45$ & 0.93 & 74.9 & $0.95 \pm 0.045 /-2.9$ & 0.90 & 38.5 \\
\hline Wendhausen AF & $0.78 \pm 0.016 /-5.8$ & 0.93 & 53.71 & $0.99 \pm 0.021 /-6.63$ & 0.94 & 33.5 \\
\hline Reiffenhausen AF & $0.85 \pm 0.034 /-4.1$ & 0.90 & 28.13 & $0.86 \pm 0.032 /-4.86$ & 0.90 & 29.7 \\
\hline
\end{tabular}

$6 \%, 5 \%$ and $1 \%$ for the agroforestry plots of Reiffenhausen, Dornburg, Forst and Wendhausen, respectively, and an overestimation by the EC-LC set-up of $8 \%$ for the monocultural agriculture plot in Dornburg relative to the conventional EC set-up (Table 2 and Fig. 12).

The dependency of the evapotranspiration estimates on the chosen high-frequency co-spectral correction method may be caused by the assumptions of each method. The Ibrom et al. (2007) high-frequency correction method was initially developed for a closed-path eddy covariance system, with a tube length of about $50 \mathrm{~m}$. The method described in Ibrom et al. (2007) takes into account the dependency of water vapour concentration measurements on relative humidity effects inside the tube. A low-pass cut-off frequency was estimated for each $30 \mathrm{~min}$ period as a function of ambient relative humidity. At least 1 month of data are suggested to estimate the low-pass cut-off frequency (LI-COR, 2015).

In contrast, the high-frequency correction method following Moncrieff et al. (1997) is purely analytical and applies a fit of the temperature co-spectra measured with the sonic anemometer on the water vapour co-spectra. This analytical method can be applied independent of meteorological measurements. Furthermore, the correction following Moncrieff et al. (1997) was recommended for either open-path EC systems or under conditions when the intake tube is short and heated (LI-COR, 2015). From an analysis of the high-frequency transfer function from Moncrieff et al. (1997) and the Lorentzian of the infinite impulse response filter from Ibrom et al. (2007) it is evident that the correction of high-frequency losses is better represented by the highfrequency spectral correction of Moncrieff et al. (1997) (see Fig. 13). The transfer function of Moncrieff et al. (1997) is shifted towards higher frequencies and lower frequencies are conserved. According to the Lorentzian (Ibrom et al., 2007) the filtering properties are more pronounced for Ibrom et al. (2007) and low frequencies $\left(<10^{-2} \mathrm{~Hz}\right)$ are attenuated. Based on the assumptions and recommendations given in Moncrieff et al. (1997) and LI-COR (2015), we decided to apply the correction of Moncrieff et al. (1997) to our EC-LC set-up.

The authors of the only known related study, published by Hill et al. (2017), present a low-cost EC set-up for measurements of $\mathrm{CO}_{2}$ and water vapour fluxes. The authors compared the low-cost EC set-up with a LI-7500 gas analyser sharing the same Campbell Scientific CSAT3 sonic anemometer. They reported a $6 \%$ flux magnitude overestimation of the latent heat flux obtained by the low-cost EC system relative to the reference EC set-up.

Flux magnitude differences observed for our low-cost setup are comparable to flux magnitude differences between conventional EC set-ups observed in a recently published study by Polonik et al. (2019). The authors found average differences between $4 \%$ and $14 \%$ between water vapour fluxes obtained by different EC set-ups consisting of three different sonic anemometers and five conventional gas analysers.

\subsection{Dependency of the latent heat flux random uncertainty on relative humidity}

Common to all sites and both set-ups was a decreasing absolute random uncertainty of the latent heat flux with increasing relative humidity (Fig. 14). At high relative humidity, turbulent latent heat fluxes were low, commonly during nighttime and bad weather conditions. Whereas during daytime and good weather conditions (generally low relative humidity), the fluxes were high. Richardson et al. (2006) described a linear dependency of the absolute random uncertainty on the magnitude of the turbulent fluxes.

For three out of five plots (Dornburg agroforestry and monoculture and Reiffenhausen agroforestry, respectively, Fig. 14a, b and e), we found a lower median random uncertainty for the latent heat fluxes obtained by the conventional EC set-up at low relative humidity, compared to the EC-LC set-up. At high relative humidity $(\geq 70 \%)$ the median of both random uncertainties was equal.

For the other two plots (Fig. 14c and d) either a higher or nearly equal mean and standard deviation was found for 


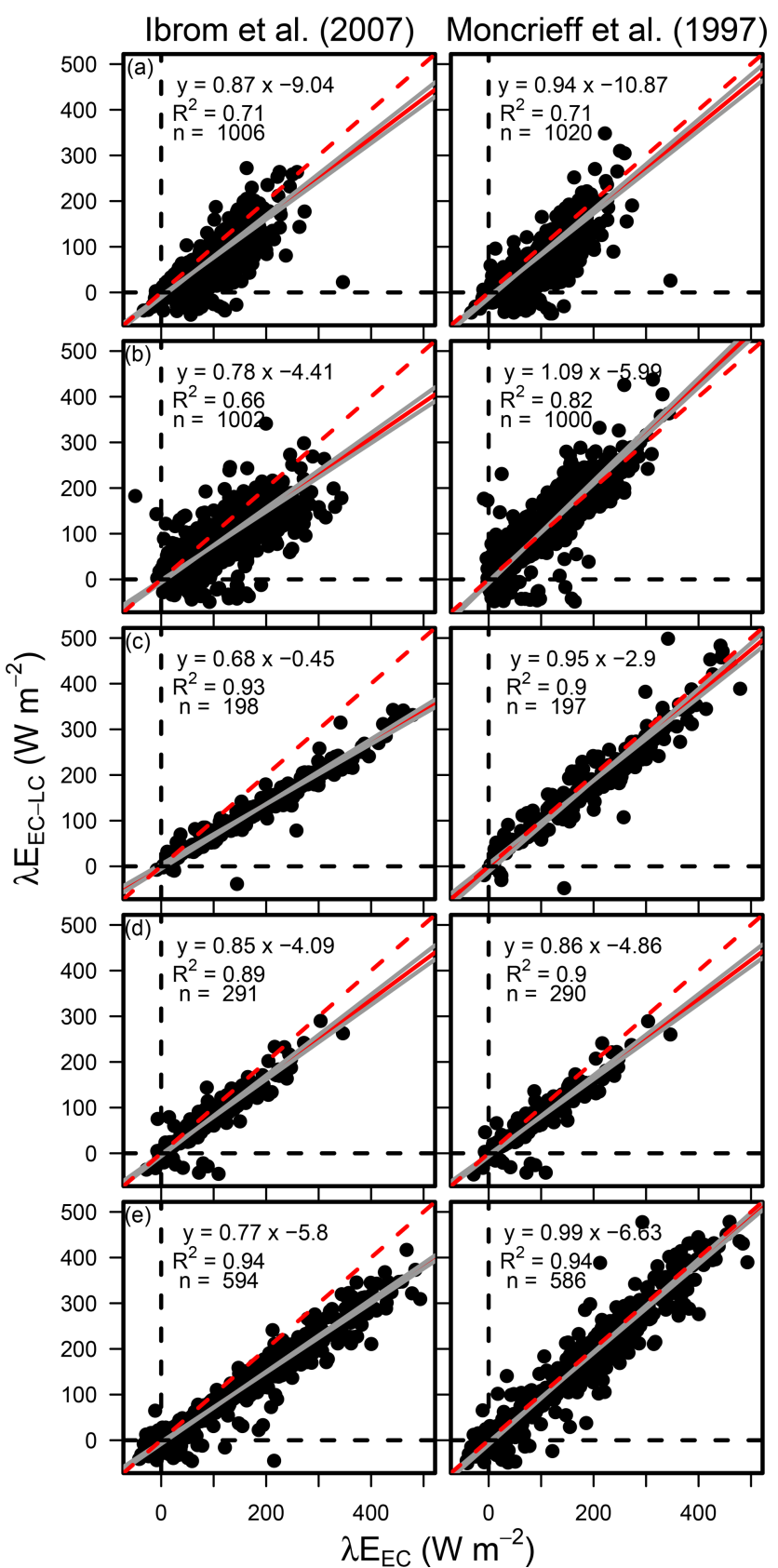

Figure 12. Scatter plots of latent heat fluxes obtained by the lowcost EC set-up vs. latent heat fluxes obtained by the conventional EC set-up for Dornburg agroforestry (a), Dornburg monoculture (b), Forst agroforestry (c), Reiffenhausen agroforestry (d) and Wendhausen agroforestry (e). Latent heat fluxes obtained by the conventional EC set-up were corrected for high-frequency losses via the high-frequency correction method of Ibrom et al. (2007), whereas the latent heat fluxes obtained by the low-cost EC setup were corrected first by the high-frequency correction method of Ibrom et al. (2007) (left-hand column) and, second, the highfrequency correction method of Moncrieff et al. (1997) (right-hand column).

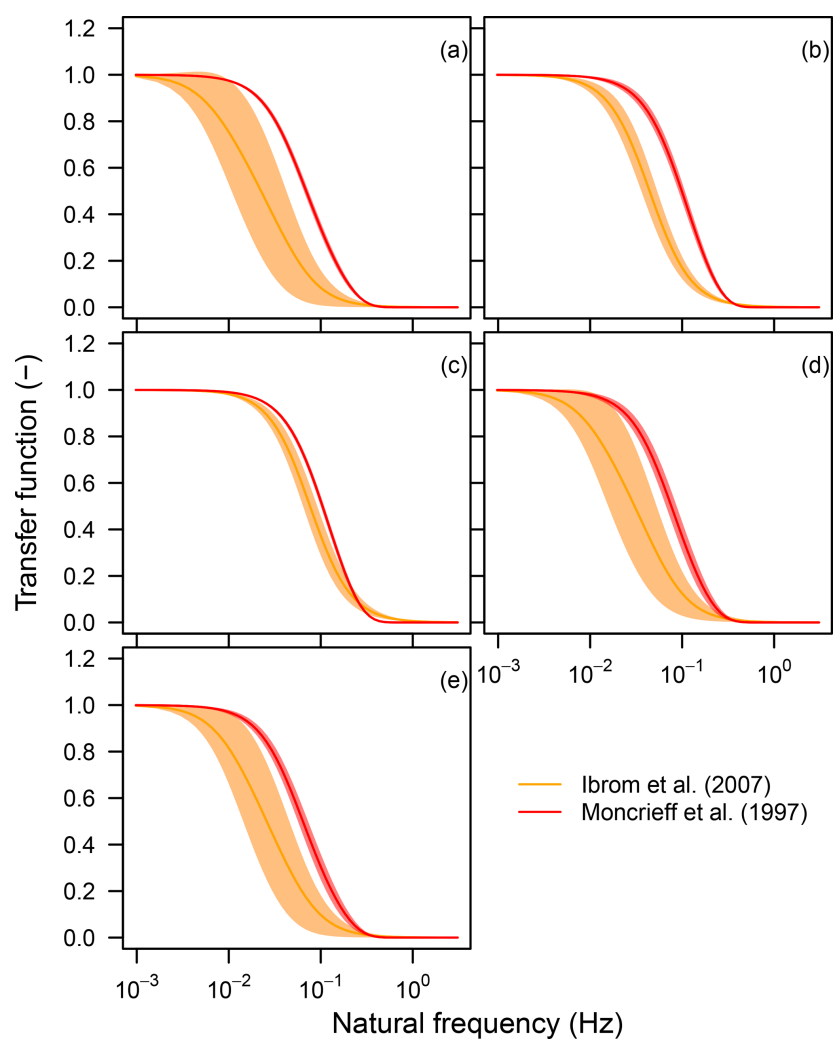

Figure 13. Mean and standard deviation of the spectral correction transfer functions vs. the natural frequency for the high-frequency spectral correction methods of Ibrom et al. (2007) and Moncrieff et al. (1997), respectively, for the following sites: Dornburg agroforestry (a), Dornburg monoculture (b), Forst agroforestry (c), Reiffenhausen agroforestry (d) and Wendhausen agroforestry (e). The transfer function of Ibrom et al. (2007) represents the mean over all infinite impulse response (IIR) filters, approximated by the Lorentzian $H_{\mathrm{IIR}}\left(f \mid f_{c}\right)=\frac{1}{1+\left(f / f_{c}\right)^{2}} . H_{\mathrm{IIR}}\left(f \mid f_{c}\right)$ was estimated for each 30 min period as per the mean ambient relative humidity.

Table 3. Mean random uncertainties and standard deviations of the latent heat fluxes obtained by the EC and EC-LC set-up.

\begin{tabular}{lrr}
\hline Site & $\overline{\sigma\left(\mathrm{LE}_{\mathrm{EC}}\right)}$ & $\overline{\sigma\left(\mathrm{LE}_{\mathrm{EC}-\mathrm{LC}}\right)}$ \\
\hline Dornburg AF & $12.94 \pm 15.82$ & $15.76 \pm 16.91$ \\
Dornburg MC & $6.27 \pm 6.01$ & $16.23 \pm 14.42$ \\
Forst AF & $30.87 \pm 18.84$ & $30.84 \pm 18.86$ \\
Wendhausen AF & $27.45 \pm 23.49$ & $23.70 \pm 20.93$ \\
Reiffenhausen AF & $13.2 \pm 14.3$ & $14.4 \pm 15.7$ \\
\hline
\end{tabular}

the latent heat flux random uncertainty from the EC set-up compared to the EC-LC set-up. Furthermore, the standard deviation of the random uncertainty of the latent heat fluxes obtained by the EC and EC-LC set-ups was of the same order of magnitude as their respective mean (Table 3). 


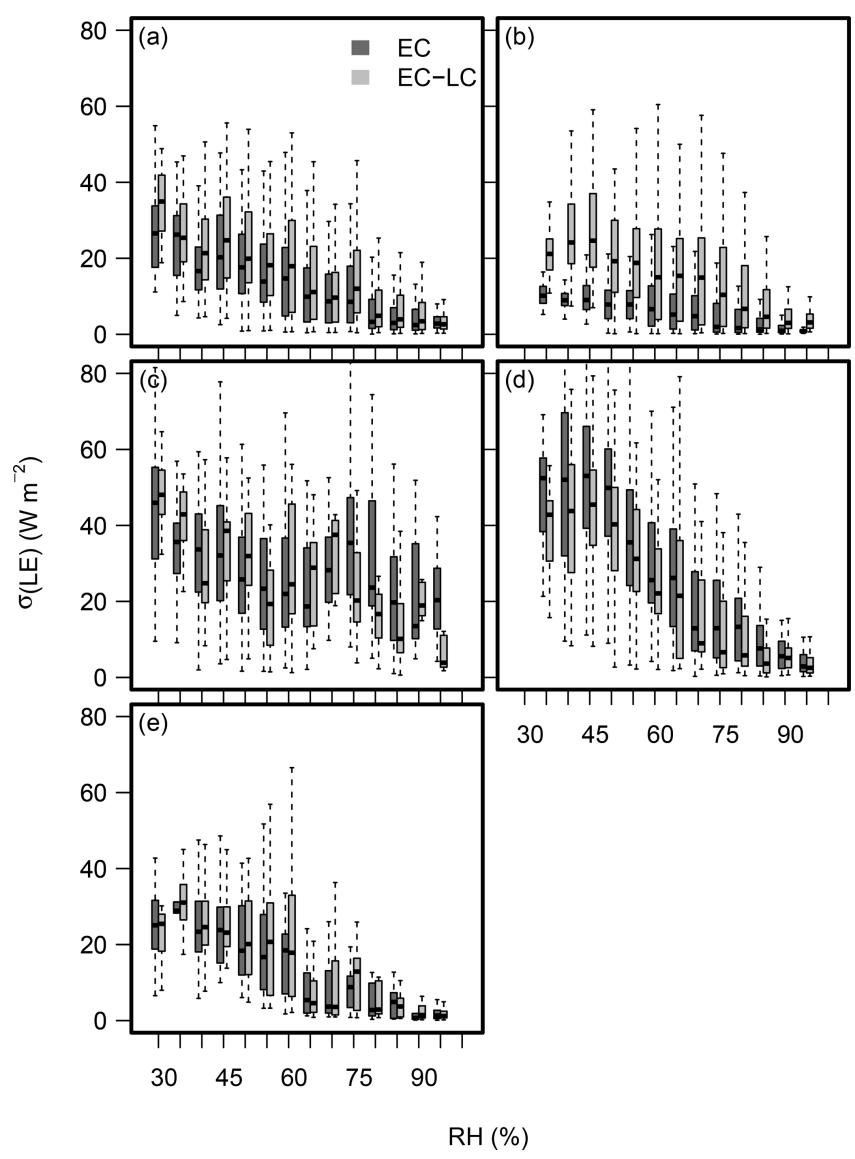

Figure 14. Box and whisker plots with random error uncertainty of the latent heat flux calculated by the EC and EC-LC set-up, respectively, vs. relative humidity bins of $5 \%$. Panels correspond to the following plots: Dornburg agroforestry (a), Dornburg monoculture (b), Forst agroforestry (c), Wendhausen agroforestry (d) and Reiffenhausen agroforestry (e).

\subsection{Distribution of differences between evapotranspiration estimates}

The median of differences between evapotranspiration rates obtained by the EC and EC-LC set-up was negative for the agroforestry plots (Fig. 15a, c, d and e). This indicates an underestimation of ET rates obtained by the EC-LC set-up, compared to the EC set-up. The distribution of the differences between evapotranspiration rates followed a skewed distribution with a tail towards negative differences of up to $\sim-0.15 \mathrm{~mm} \mathrm{~h}^{-1}$. The tail towards positive values declined sharply after the maximum of the distribution.

At the monocultural agriculture plot at Dornburg (Fig. 15b) there was no significant difference in the median evapotranspiration rates of the two set-ups. The differences were equally distributed towards overestimated and underestimated ET rates until a zero density of $\pm 0.1 \mathrm{~mm} \mathrm{~h}^{-1}$.
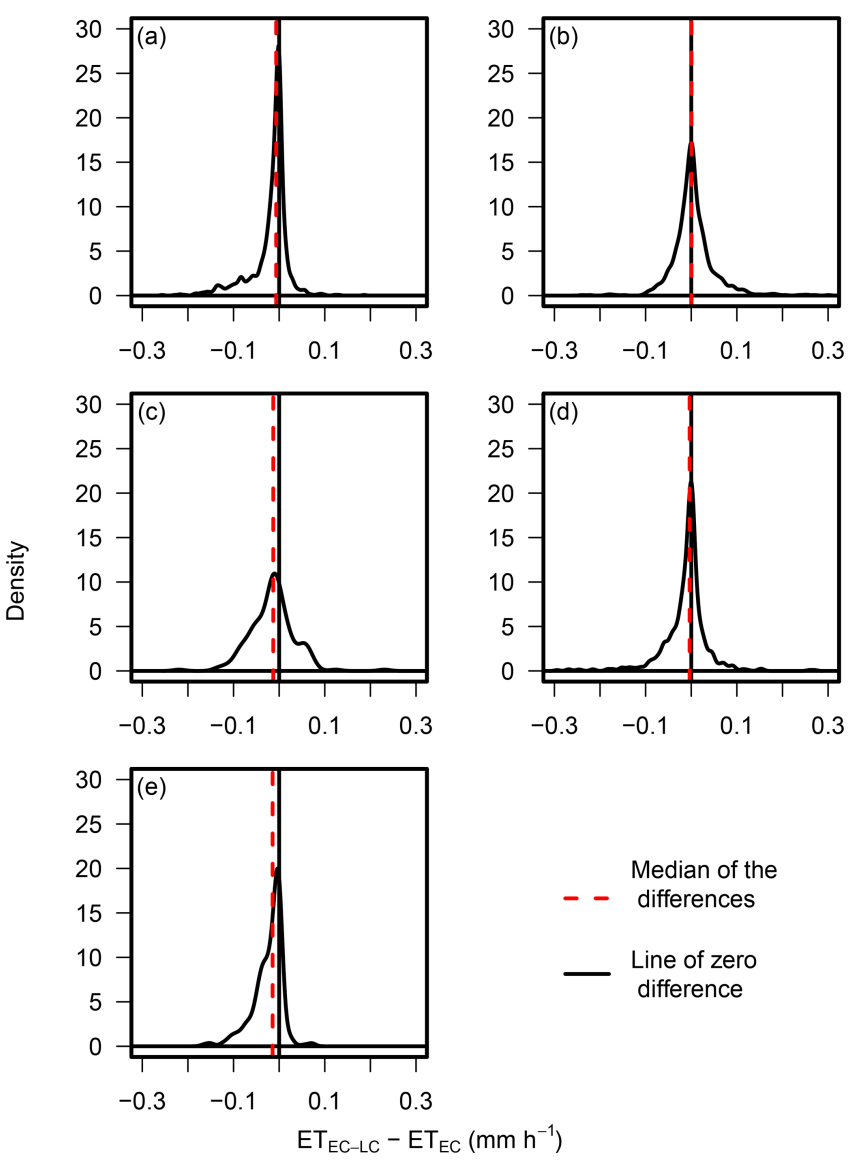

Figure 15. Density distribution of differences between evapotranspiration rates obtained by the EC and EC-LC set-up for Dornburg agroforestry (a), Dornburg monoculture (b), Forst agroforestry (c), Wendhausen agroforestry (d) and Reiffenhausen agroforestry (e).

\subsection{Cumulative evapotranspiration rates}

We observed a lower cumulative evapotranspiration for the EC-LC set-up at all agroforestry plots, relative to the conventional EC set-up (Figs. 16 and 17). In contrast, a higher cumulative ET was found for the EC-LC set-up at the monocultural agriculture plot in Dornburg. The plot of cumulative ET lines in Fig. 17a I indicates a discrepancy between the cumulative ET lines at the agroforestry plot in Dornburg. This is caused by a period of poor performance of the low-cost set-up. After removing this period from the dataset, we still observed higher ET sums at the AF than at the MC plot but now differences were comparable to differences observed at the other plots, as indicated by the shaded bars in Fig. 16. In general, the observation of underestimated or overestimated (agroforestry vs. monocultural plots) ET rates obtained by the EC-LC set-up relative to the EC set-up is in agreement with the linear regression results presented in Sect. 3.7. 


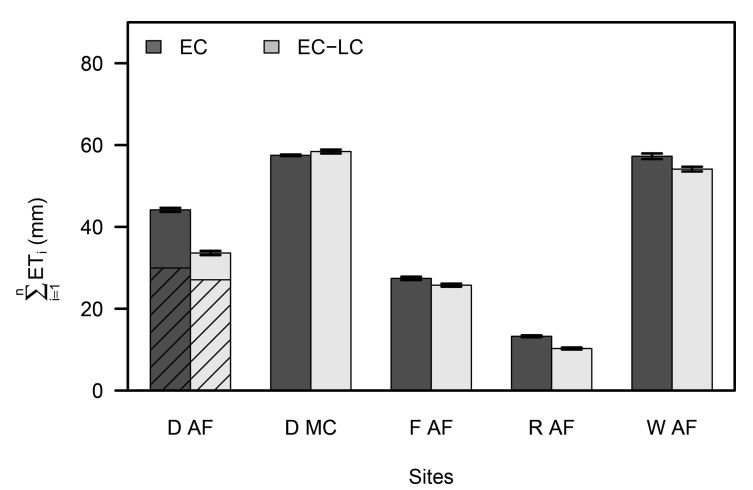

Figure 16. Cumulative evapotranspiration rates for the EC and ECLC set-ups for Dornburg agroforestry (D AF), Dornburg monoculture (D MC), Forst agroforestry (F AF), Wendhausen agroforestry (W AF) and Reiffenhausen agroforestry (R AF) over the respective campaign periods (Table A2). The error bars correspond to the summed random uncertainties. The shaded area of the Dornburg agroforestry data corresponds to the cumulative sum of ET, filtered for the period of poor performance of the EC-LC set-up. Incomplete records with either EC or EC-LC missing were omitted.
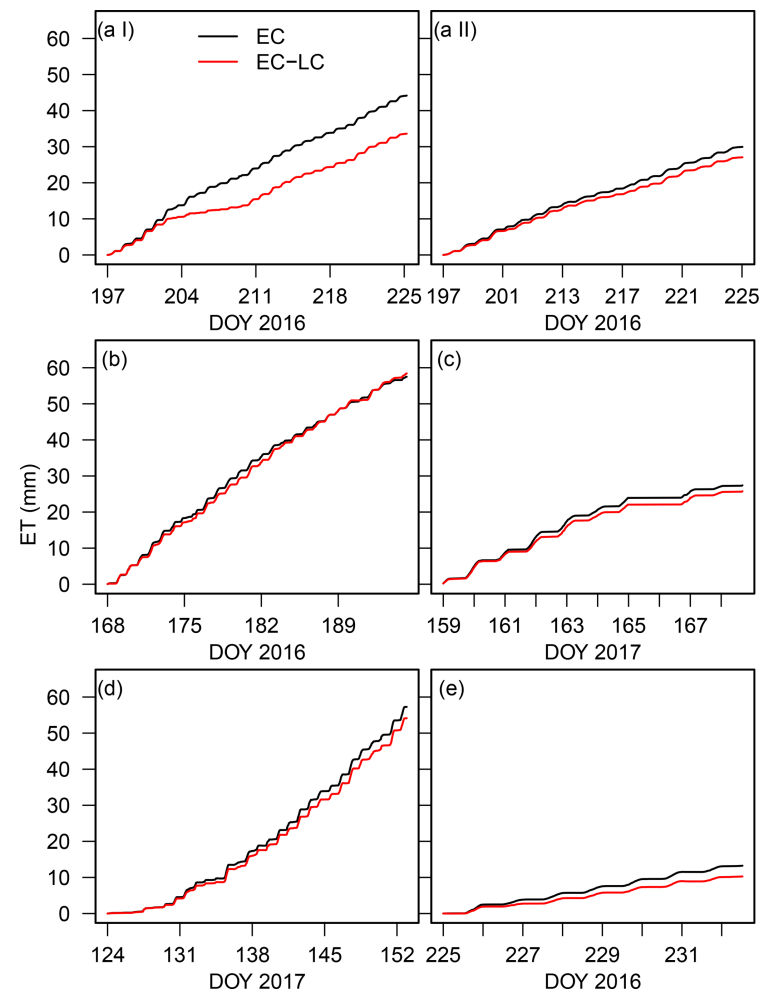

Figure 17. The $30 \mathrm{~min}$ cumulative evapotranspiration rates for the EC (solid black line) and EC-LC (solid red line) set-ups for Dornburg agroforestry with unfiltered data for the period of poor performance of the EC-LC set-up (a I), Dornburg agroforestry with filtered data for the period of poor performance of the EC-LC setup (a II), Dornburg monoculture (b), Forst agroforestry (c), Wendhausen agroforestry (d) and Reiffenhausen agroforestry (e) over their respective campaign periods (Table A2). Incomplete records with either EC or EC-LC missing were omitted.

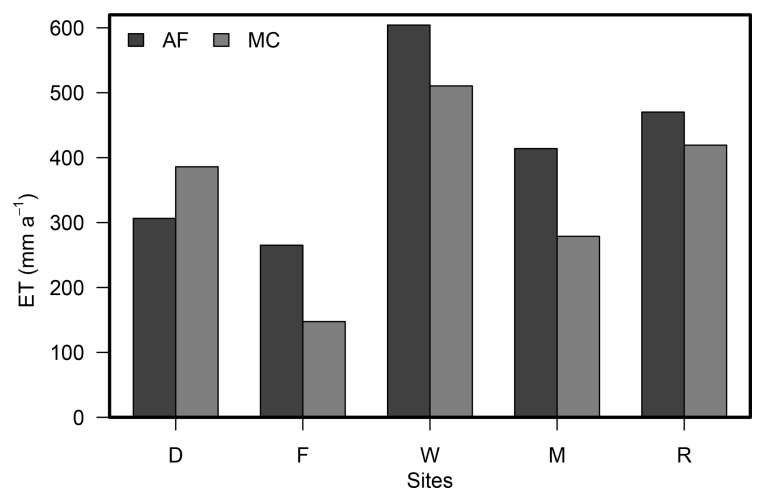

Figure 18. Cumulative evapotranspiration rates obtained by the EC-LC set-up at sites Dornburg (D), Forst (F), Wendhausen (W), Mariensee (M) and Reiffenhausen (R) for 2016. Incomplete records with either agroforestry or monoculture missing were omitted. Gapfilling was performed by multiplying the summed ET using the ratio of the number of maximum possible records to the number of missing records.

\subsection{Annual cumulative ET rates for the agroforestry and the monocultural plot}

We wanted to understand how evapotranspiration of agroforestry and monoculture differed. We deployed the EC-LC set-up as a convenient means to obtain continuous long-term evapotranspiration estimates at $30 \mathrm{~min}$ resolution. Here, we present annual cumulative sums of 30 min evapotranspiration rates for 2016 from all sites, independent of the measuring campaigns.

At the Dornburg site, annual cumulative evapotranspiration rates were higher at the monocultural agriculture plot compared to the agroforestry plot (Fig. 18), which might be caused by the wind-exposed location of the monocultural agriculture plot. The higher wind speed at the monocultural agriculture plot increases the boundary layer conductance, and therefore both soil evaporation and plant transpiration increase.

At the remaining four out of five sites the annual cumulative evapotranspiration rates were higher at the agroforestry plots than at the monocultural agriculture plots (Forst, Wendhausen, Mariensee and Reiffenhausen, Fig. 18). We interpret higher evapotranspiration rates at the agroforestry than at the monocultural plots as an effect of the increased biomass at the agroforestry plot, originating both from the trees and the crops grown between the tree strips. Despite the presence of a leeward side with reduced evapotranspiration caused by the wind reduction and the increased shade, both crops and trees are affected by wind on the windward site. More turbulent conditions are present at the agroforestry plots, caused by the presence of the tree strips, which is indicated by a higher mean roughness length at the agroforestry plots compared to the conventional agriculture plots, as shown in Fig. A1 for all sites. 


\section{Conclusions}

We presented a new low-cost eddy covariance set-up, which is comprised of a conventional ultrasonic anemometer and a low-cost thermohygrometer. We applied the eddy covariance method on the vertical velocity component and the water vapour mole fraction derived from the thermohygrometer. The advantages of the set-up are low material costs and low power consumption. The performance of the EC-LC set-up was comparable to the EC set-up with regards to mean evapotranspiration rates. The set-up-specific differences in mean evapotranspiration rates were insignificant compared to the variability between sites.

In detail, we were able to explain more than $80 \%$ of the variability in evapotranspiration obtained by the conventional eddy covariance set-up by the variability of the low-cost eddy covariance set-up. The low-cost eddy covariance set-up is a good alternative to the conventional EC set-up for both conventional agriculture systems and agroforestry ecosystems at a temporal resolution of $30 \mathrm{~min}$.
We showed that under conditions of high relative humidity and low air temperature the flux random error uncertainty of both set-ups was highest. ET rates obtained by the EC-LC set-up with limited frequency response had a lower relative difference with ET rates obtained by the EC set-up at the $10 \mathrm{~m}$ measurement height (AF) than at the $3.5 \mathrm{~m}$ height given a larger contribution of low-frequency eddies at the larger measurement height.

We anticipate potential applications of the EC-LC setup in experiments comparing different treatments (management effects, different agriculture systems, water use) and chronosequences after fires or clear cuts. The set-up provides a tool for replicated ET measurements across different ecosystems. With low-cost instruments, flux measurements at existing flux networks such as FLUXNET, ICOS or NEON can be complemented and provided at remote and so-far under-represented sites.

Data availability. All data used for the figures presented here are provided at https://doi.org/10.5281/zenodo.3356837 (Markwitz and Siebicke, 2019). 


\section{Appendix A}

Table A1. Site locations, agroforestry geometry and stand characteristics.

\begin{tabular}{lrrrrr}
\hline Site & Coordinates & $\begin{array}{r}\text { No. of } \\
\text { tree alleys }\end{array}$ & $\begin{array}{r}\text { System size } \\
{\left[\mathrm{m}^{2}\right]}\end{array}$ & $\begin{array}{r}\text { Relative } \\
\text { tree cover }\end{array}$ & Tree height [m] \\
\hline Reiffenhausen & $51^{\circ} 24^{\prime} \mathrm{N} 9^{\circ} 59^{\prime} \mathrm{E}$ & 3 & 18700 & $72 \%$ & $4.73 \pm 0.32(n=69)($ Malec, 2017) \\
\hline Mariensee & $52^{\circ} 34^{\prime} \mathrm{N} 9^{\circ} 28^{\prime} \mathrm{E}$ & 3 & 69260 & $6 \%$ & $4.01 \pm 0.33(n=96)($ Swieter and Langhof, 2017) \\
\hline Wendhausen & $52^{\circ} 20^{\prime} \mathrm{N} 10^{\circ} 38^{\prime} \mathrm{E}$ & 6 & 179738 & $11.52 \%$ & $6.21 \pm 0.4(n=114)($ Swieter and Langhof, 2017) \\
\hline Forst & $51^{\circ} 47^{\prime} \mathrm{N} 14^{\circ} 38^{\prime} \mathrm{E}$ & 7 & 391300 & $12 \%$ & $6.5 \pm 1.8(n=161)($ Seserman, 2017) \\
\hline Dornburg & $51^{\circ} 47^{\prime} \mathrm{N} 11^{\circ} 39^{\prime} \mathrm{E}$ & 7 & 508723 & $8 \%$ & $6.4 \pm 0.64(n=160)($ Rudolf, 2017) \\
\hline
\end{tabular}

Table A2. Temporal extent of the EC measurement campaigns.

\begin{tabular}{ll}
\hline Site & Campaign period \\
\hline Dornburg Conv & 16 June to 14 July 2016 \\
Dornburg AF & 14 July to 12 August 2016 \\
Reiffenhausen AF & 12 August to 14 September 2016 \\
Wendhausen & 3 May to 2 June 2017 \\
Forst & 8 June to 8 July 2017 \\
Mariensee & 21 July to 19 September 2017 \\
\hline
\end{tabular}

Table A3. Instrument separation of the gas analyser relative to the centre of the sonic anemometer in the northern, eastern and vertical direction.

\begin{tabular}{lrrrr}
\hline Site & $\begin{array}{r}\text { Northern } \\
{[\mathrm{cm}]}\end{array}$ & $\begin{array}{r}\text { Eastern } \\
{[\mathrm{cm}]}\end{array}$ & $\begin{array}{r}\text { Vertical } \\
{[\mathrm{cm}]}\end{array}$ & Year \\
\hline Dornburg MC & 6 & 14 & -21 & 2016 \\
Dornburg AF & -27 & 4 & -26 & 2016 \\
Reiffenhausen AF & 1 & 9 & -20 & 2016 \\
Wendhausen AF & -10 & 0 & -20 & 2017 \\
Forst AF & -12 & 0 & -22 & 2017 \\
\hline
\end{tabular}

Table A4. Mean air temperature, $T$, vapour pressure deficit, VPD, global radiation, $R_{\mathrm{G}}$ and the cumulative precipitation, Rain, for the respective site and measurement period.

\begin{tabular}{lrrcr}
\hline Site & $\begin{array}{r}T \\
\left({ }^{\circ} \mathrm{C}\right)\end{array}$ & $\begin{array}{r}\mathrm{VPD} \\
(\mathrm{hPa})\end{array}$ & $\begin{array}{c}R_{\mathrm{G}} \\
\left(\mathrm{W} \mathrm{m}^{-2}\right)\end{array}$ & $\begin{array}{r}\text { Rain } \\
(\mathrm{mm})\end{array}$ \\
\hline Dornburg MC & 18.6 & 7.35 & 212.6 & 2.1 \\
Dornburg AF & 19.0 & 6.41 & 200.7 & 57.1 \\
Reiffenhausen AF & 19.31 & 8.02 & 219.1 & 26.3 \\
Wendhausen AF & 16.6 & 5.4 & 235.0 & 48.6 \\
Forst AF & 21.4 & 12.02 & 358.8 & 18.9 \\
\hline
\end{tabular}

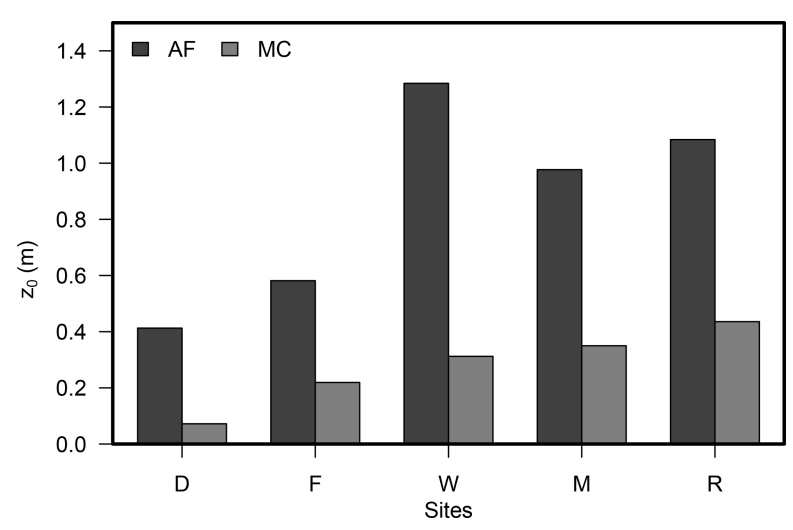

Figure A1. Mean roughness length at sites Dornburg (D), Forst (F), Wendhausen (W), Mariensee (M) and Reiffenhausen (R) for 2016. 
Author contributions. CM designed and performed the field work, analysed the data, and wrote the manuscript. LS wrote the project's scientific proposal; acquired the funding as part of the BonaRes SIGNAL consortium; and contributed to field work, analysis, and manuscript writing.

Competing interests. The authors declare that they have no conflict of interest.

Acknowledgements. We wish to acknowledge contributions by Alexander Knohl and Mathias Herbst to the BonaRes SIGNAL proposal and project design, as well as the technical support in the field work received by Frank Tiedemann, Edgar Tunsch, Dietmar Fellert, Martin Lindenberg, Johann Peters (bioclimatology group) and Dirk Böttger (soil science group of tropical and subtropical ecosystems) from the University of Göttingen.

Financial support. This research has been supported by the German Federal Ministry of Education and Research (BMBF, project BonaRes, Module A, SIGNAL 031A562A) and by the Deutsche Forschungsgemeinschaft (INST 186/1118-1 FUGG).

This open-access publication was funded by the University of Göttingen.

Review statement. This paper was edited by Christian Brümmer and reviewed by Timothy Hill and two anonymous referees.

\section{References}

Aubinet, M., Vesala, T., and Papale, D. (Eds.): Eddy Covariance: A Practica Guide to Measurement and Data Analysis, Springer Dordrecht, Heidelberg, London, New York, https://doi.org/10.1007/978-94-007-2351-1, 2012.

Baldocchi, D. D.: Assessing the eddy covariance technique for evaluating carbon dioxide exchange rates of ecosystems: past, present and future, Glob. Change Biol., 9, 479-492, https://doi.org/10.1046/j.1365-2486.2003.00629.x, 2003.

Baldocchi, D. D.: Measuring fluxes of trace gases and energy between ecosystems and the atmosphere - the state and future of the eddy covariance method, Glob. Change Biol., 20, 3600-3609, https://doi.org/10.1111/gcb.12649, 2014.

Bosch Sensortec GmbH: BME280: Combined humidity and pressure sensor, 2016.

Bundesamt für Kartographie und Geodäsie: Frankfurt am Main, available at: https://www.bkg.bund.de/DE/Home/home.html (last access: 21 August 2019), 2011.

Burba, G., Schmidt, A., Scott, R. L., Nakai, T., Kathilankal, J., Fratini, G., Hanson, C., Law, B., Mcdermitt, D. K., Eckles, R., Furtaw, M., and Velgersdyk, M.: Calculating $\mathrm{CO}_{2}$ and $\mathrm{H}_{2} \mathrm{O}$ eddy covariance fluxes from an enclosed gas analyzer using an instantaneous mixing ratio, Glob. Change Biol., 18, 385-399, https://doi.org/10.1111/j.1365-2486.2011.02536.x, 2012.
Davis, P. A., Brown, J. C., Saunders, M., Lanigan, G., Wright, E., Fortune, T., Burke, J., Connolly, J., Jones, M. B., and Osborne, B.: Assessing the effects of agricultural management practices on carbon fluxes: Spatial variation and the need for replicated estimates of Net Ecosystem Exchange, Agr. Forest Meteorol., 150, 564-574, https://doi.org/10.1016/j.agrformet.2010.01.021, 2010.

De Stefano, A. and Jacobson, M. G.: Soil carbon sequestration in agroforestry systems: a meta-analysis, Agroforest. Syst., 92, 285-299, https://doi.org/10.1007/s10457-017-0147-9, 2018.

Dias, N. L., Duarte, H. F., and Maggiotto, S. R.: An attenuated eddy covariance method for latent heat flux measurements, Water Resour. Res., 43, W04415, https://doi.org/10.1029/2006WR005259, 2007.

Eugster, W. and Plüss, P.: A fault-tolerant eddy covariance system for measuring $\mathrm{CH}_{4}$ fluxes, Agr. Forest. Meteorol., 150, 841-851, https://doi.org/10.1016/j.agrformet.2009.12.008, 2010.

Farahani, H. J., Howell, T. A., Shuttleworth, W. J., and Bausch, W. C.: Evapotranspiration: Progress in Measurement and Modeling in Agriculture, T. ASABE, 50, 1627-1638, 2007.

Foken, T.: Micrometorology, vol. 1, Springer-Verlag Berlin Heidelberg, Bayreuth, 2008.

Foken, T., Göckede, M., Mauder, M., Mahrt, L., Amiro, B., and Munger, W.: Post-field data quality control, Handbook of Micrometeorology, 29, 181-208, https://doi.org/10.1007/1-40202265-4_9, 2004.

Fratini, G., Ibrom, A., Arriga, N., Burba, G., and Papale, D.: Relative humidity effects on water vapour fluxes measured with closed-path eddy-covariance systems with short sampling lines, Agr. Forest Meteorol., 165, 53-63, https://doi.org/10.1016/j.agrformet.2012.05.018, 2012.

Hill, T., Chocholek, M., and Clement, R.: The case for increasing the statistical power of eddy covariance ecosystem studies: why, where and how?, Glob. Change Biol., 23, 2154-2165, https://doi.org/10.1111/gcb.13547, 2017.

Hollinger, D. Y. and Richardson, A. D.: Uncertainty in eddy covariance measurements and its application to physiological models, Tree Physiol., 25, 873-885, https://doi.org/10.1093/treephys/25.7.873, 2005.

Ibrom, A., Dellwik, E., Flyvbjerg, H., Jensen, N. O., and Pilegaard, K.: Strong low-pass filtering effects on water vapour flux measurements with closed-path eddy correlation systems, Agr. Forest Meteorol., 147, 140-156, https://doi.org/10.1016/j.agrformet.2007.07.007, 2007.

Kaimal, J. and Finnigan, J.: Atmospheric boundary layer flows: Their structure and measurement, Oxford University Press, New York, 1994.

Kaimal, J. C., Wyngaard, J. C., Izumi, Y., and Coté, O. R.: Spectral characteristics of surface layer turbulence, Q. J. Roy. Meteor. Soc., 98, 563-589, https://doi.org/10.1002/qj.49709841707, 1972.

Kljun, N., Calanca, P., Rotach, M. W., and Schmid, H. P.: A simple two-dimensional parameterisation for Flux Footprint Prediction (FFP), Geosci. Model Dev., 8, 3695-3713, https://doi.org/10.5194/gmd-8-3695-2015, 2015.

Kolmogorov, A. N.: The local structure of turbulence in incompressible viscous fluid for very large Reynolds numbers, P. Roy. Soc. Lond. A Mat., 434, 9-13, https://doi.org/10.1098/rspa.1991.0075, 1991. 
Kristensen, L. and Fritzjarrals, D. R.: The Effect of Line Averaging on Scalar Flux Measurements with a Sonic Anemometer near the Surface, J. Atmos. Ocean. Tech., 1, 138-146, https://doi.org/10.1175/15200426(1984)001<0138:TEOLAO>2.0.CO;2 1984.

Legendre, P. and Oksanen, J.: Imodel2: Model II Regression, Tech. rep., 1.7-3, available at: https://cran.r-project.org/web/packages/ lmodel2/lmodel2.pdf (last access: 21 August 2019), 2018.

Lenschow, D. H. and Raupach, M. R.: The attenuation of fluctuations in scalar concentrations through sampling tubes, J. Geophys. Res., 96, 15259, https://doi.org/10.1029/91JD01437, 1991.

Leuning, R. and Moncrieff, J.: Eddy-covariance $\mathrm{CO}_{2}$ flux measurements using open- and closed-path $\mathrm{CO}_{2}$ analysers: Corrections for analyser water vapour sensitivity and damping of fluctuations in air sampling tubes, Bound.-Lay. Meteorol., 53, 63-76, https://doi.org/10.1007/BF00122463, 1990.

LI-COR, Inc.: EddyPro 6 - Eddy Covariance Software Instruction Manual, Tech. rep., 977-12025, 10th edn., 2015.

Malec, S.: University of Kassel, Grassland Science and Renewable Plant Resources, unpublished data, 2017.

Mann, J. and Lenschow, D. H.: Errors in airborne flux measurements, J. Geophys. Res., 99, 14519, https://doi.org/10.1029/94JD00737, 1994.

Markwitz, C. and Siebicke, L.: Data set supporting journal article: Markwitz, C. and Siebicke, L.: "Low-cost eddy covariance: a case study of evapotranspiration over agroforestry in Germany", Atmos. Meas. Tech., 2019 (Version 1) [Data set], Zenodo, https://doi.org/10.5281/zenodo.3356837, 2019.

Mauder, M. and Foken, T.: Impact of post-field data processing on eddy covariance flux estimates and energy balance closure, Meteorol. Z., 15, 597-609, https://doi.org/10.1127/09412948/2006/0167, 2006.

Mauder, M. and Foken, T.: Documentation and Instruction Manual of the Eddy-Covariance Software Package TK3, Universität Bayreuth, Abt. Mikrometeorologie, 46 edn., 2011.

Moncrieff, J., Massheder, J., de Bruin, H., Elbers, J., Friborg, T., Heusinkveld, B., Kabat, P., Scott, S., Soegaard, H., and Verhoef, A.: A system to measure surface fluxes of momentum, sensible heat, water vapour and carbon dioxide, J. Hydrol., 188-189, 589611, https://doi.org/10.1016/S0022-1694(96)03194-0, 1997.

Moncrieff, J., Clement, R., Finnigan, J., and Meyers, T.: Averaging, Detrending, and Filtering of Eddy Covariance Time Series, Handbook of Micrometeorology, 29, 7-31, https://doi.org/10.1007/1-4020-2265-4_2, 2004.

Polonik, P., Chan, W., Billesbach, D., Burba, G., Li, J., Nottrott, A., Bogoev, I., Conrad, B., and Biraud, S.: Comparison of gas analyzers for eddy covariance: Effects of analyzer type and spectral corrections on fluxes, Agr. Forest Meteorol., 272-273, 128-142, https://doi.org/10.1016/j.agrformet.2019.02.010, 2019.
Richardson, A. D., Hollinger, D. Y., Burba, G. G., Davis, K. J., Flanagan, L. B., Katul, G. G., William Munger, J., Ricciuto, D. M., Stoy, P. C., Suyker, A. E., Verma, S. B., and Wofsy, S. C.: A multi-site analysis of random error in tower-based measurements of carbon and energy fluxes, Agr. Forest Meteorol., 136, 1-18, https://doi.org/10.1016/j.agrformet.2006.01.007, 2006.

Rudolf, C.: Thurengian state office of agriculture and rural areas, unpublished data, 2017.

Schmid, H. P.: Footprint modeling for vegetation atmosphere exchange studies: A review and perspective, Agr. Forest Meteorol., 113, 159-183, https://doi.org/10.1016/S0168-1923(02)00107-7, 2002.

Schotanus, P., Nieuwstadt, F. T. M., and Bruin, D. H. A. R.: Temperature measurements with a SONIC anemometer and its application to heat and moisture fluxes, Bound.-Lay. Meteorol., 26, 81-93, https://doi.org/10.1007/BF00164332, 1983.

Seserman, D.-M.: Brandenburg University of Technology, CottbusSenftenberg, Soil protection and recultivation, unpublished data, 2017.

Stull, R. B.: An introduction to boundary layer meteorology, Kluwer Acadamic Publishers, Dordrecht, Boston, London, https://doi.org/10.1007/978-94-009-3027-8, 1989.

Swieter, A. and Langhof, M.: Julius Kühn-Institut, Institute for crop and soil science, unpublished data, 2017.

Tang, X., Li, H., Desai, A. R., Nagy, Z., Luo, J., Kolb, T. E., Olioso, A., Xu, X., Yao, L., Kutsch, W., Pilegaard, K., Köstner, B., and Ammann, C.: How is water-use efficiency of terrestrial ecosystems distributed and changing on Earth?, Scientific Reports, 4, 7483, https://doi.org/10.1038/srep07483, 2014.

Trapletti, A. and Hornik, K.: tseries: Time Series Analysis and Computational Finance, Tech. rep., Version: 0.10-47, available at: https://cran.r-project.org/package=tseries (last access: $21 \mathrm{Au}$ gust 2019), 2017.

Vickers, D. and Mahrt, L.: Quality control and flux sampling problems for tower and aircraft data, J. Atmos. Ocean. Tech., 14, 512-526, https://doi.org/10.1175/15200426(1997)014<0512:QCAFSP>2.0.CO;2, 1997.

Webb, E. K., Pearman, G. I., and Leuning, R.: Correction of flux measurements for density effects due to heat and water vapour transfer, Q. J. Roy. Meteor. Soc., 106, 85-100, https://doi.org/10.1002/QJ.49710644707, 1980. 